\title{
In situ grown bifacial graphene stabilizes composite electrode for efficient perovskite solar cells
}

\section{Liyuan Han ( $\nabla$ han.liyuan@sjtu.edu.cn )}

State Key Laboratory of Metal Matrix Composites, School of Materials Science and Engineering, Shanghai Jiao Tong University, 800 Dongchuan RD https://orcid.org/0000-0001-9766-9015

\section{Xuesong Lin}

State Key Laboratory of Metal Matrix Composites, Shanghai Jiao Tong University

\section{Hongzhen Su}

State Key Laboratory of Metal Matrix Composites, School of Materials Science and Engineering, Shanghai Jiao Tong University, 800 Dongchuan RD

\section{Sifan He}

Engineering Research Center for Nanophotonics and Advanced Instrument, Ministry of Education, School of Physics and Materials Science, East China Normal University, Shanghai 200241, China.

\section{Yenan Song}

Engineering Research Center for Nanophotonics and Advanced Instrument, Ministry of Education, School of Physics and Materials Science, East China Normal University, Shanghai 200241, China.

\section{Yanbo Wang}

Shanghai Jiao Tong University https://orcid.org/0000-0002-6061-7577

\section{Zhenzhen Qin}

State Key Laboratory of Metal Matrix Composites, School of Materials Science and Engineering, Shanghai Jiao Tong University, 800 Dongchuan RD

\section{Yongzhen Wu}

Key Laboratory for Advanced Materials and Institute of Fine Chemicals, School of Chemistry and Molecular Engineering, East China University of Science and Technology, Shanghai 200237, China.

\section{Xudong Yang}

Shanghai Jiao Tong University https://orcid.org/0000-0002-7398-4229

\section{Qifeng Han}

Shanghai Jiao Tong University

\section{Junfeng Fang}

Engineering Research Center for Nanophotonics and Advanced Instrument, Ministry of Education, School of Physics and Materials Science, East China Normal University, Shanghai 200241, China.

\section{Michael Graetzel}

École Polytechnique Fédérale de Lausanne https://orcid.org/0000-0002-0068-0195 
Physical Sciences - Article

Keywords: perovskite solar cells, composite electrode, Cu-Ni alloy

Posted Date: August 9th, 2021

DOl: https://doi.org/10.21203/rs.3.rs-744594/v1

License: (c) (i) This work is licensed under a Creative Commons Attribution 4.0 International License. Read Full License

Version of Record: A version of this preprint was published at Nature Energy on May 30th, 2022. See the published version at https://doi.org/10.1038/s41560-022-01038-1. 


\section{In situ grown bifacial graphene stabilizes composite electrode for efficient perovskite solar cells}

Xuesong Lin ${ }^{1,6}$, Hongzhen $\mathrm{Su}^{1,6}$, Sifan $\mathrm{He}^{3,6}$, Yenan Song ${ }^{3,6}$, Yanbo Wang ${ }^{1 *}$, Zhenzhen Qin ${ }^{1}$, Yongzhen $\mathrm{Wu}^{4}$, Xudong Yang ${ }^{1}$, Qifeng $\mathrm{Han}^{1}$, Junfeng Fang ${ }^{3}$, Michael Grätzel ${ }^{5}$, Liyuan $\operatorname{Han}^{1,2 *}$

${ }^{1}$ State Key Laboratory of Metal Matrix Composites, Shanghai Jiao Tong University, Shanghai 200240, China.

${ }^{2}$ Special Division of Environmental and Energy Science, Komaba Organization for Educational Excellence, College of Arts and Sciences, University of Tokyo, Tokyo 1538902, Japan.

${ }^{3}$ Engineering Research Center for Nanophotonics and Advanced Instrument, Ministry of Education, School of Physics and Materials Science, East China Normal University, Shanghai 200241, China.

${ }^{4}$ Key Laboratory for Advanced Materials and Institute of Fine Chemicals, School of Chemistry and Molecular Engineering, East China University of Science and Technology, Shanghai 200237, China.

${ }^{5}$ Laboratory of Photonics and Interfaces, Institute of Chemical Sciences and Engineering, École Polytechnique Fédérale de Lausanne (EPFL), Lausanne, Switzerland. 
${ }^{6}$ These authors contributed equally to this work.

*email: sjtu-wyb@sjtu.edu.cn (Y.B.W.); han.liyuan@sjtu.edu.cn (L.Y.H.)

Instability of rear electrodes undermines the long-term operational durability of efficient perovskite solar cells (PSCs). Here, a composite electrode of copper-nickel (Cu-Ni) alloy stabilized by in situ grown bifacial graphene is designed. The alloying makes the work function of $\mathrm{Cu}$ suitable for regular PSCs and $\mathrm{Cu}-\mathrm{Ni}$ is the ideal substrate for preparing high-quality graphene via chemical vapor deposition, which simultaneously protects the device from oxygen, water and internal components reaction. To rivet the composite electrode with semi-device, a thermoplastic copolymer is employed as an adhesive layer during hot pressing. The resultant device achieved power conversion efficiency of $\mathbf{2 4 . 3 4 \%}$ with significantly improved stability; the devices without encapsulation retained $97 \%$ of their initial efficiency after the damp heat test at $85^{\circ} \mathrm{C}$ with relative humidity of $85 \%$ for 1440 hours and the encapsulated devices maintained $95 \%$ of their initial efficiencies after maximum power point tracking under continuous 1 sun illumination for 5000 hours.

Metal halide perovskite solar cells (PSCs) have attracted great attention in both academia and industry owing to their excellent optoelectronic performance and low manufacturing $\operatorname{costs}^{1-6}$. However, for PSCs to realize commercialization, they must survive the long-term natural erosion imposed by oxygen, moisture, light and heat ${ }^{7,8}$. Thanks to the optimization of the perovskite materials, charge transport materials and the interface layers ${ }^{9-12}$, the 
operational stability of PSCs has made a great progress, but one of the key functional layers, rear electrode, is still prone to fail, which limits the overall durability of efficient PSCs ${ }^{13-}$ 14.

Silver (Ag) and aluminum (Al) are commonly used rear electrodes, whereas they tend to react with migrated halide anions from perovskite to form resistive compounds such as $\mathrm{AgI}$ and $\mathrm{AlI}_{3}{ }^{15-17}$. In the case of gold $(\mathrm{Au})$, although the formation enthalpy of Au-I is much higher, $\mathrm{Au}$ atoms can diffuse into the perovskite to form deep-level defects of $\mathrm{AuPb}$, which act as efficient non-radiative recombination centers ${ }^{18}$. In addition, the use of noble metals comes at a high price and implies more stringent requirements for vacuum and temperature, which will significantly increase the manufacturing costs. To suppress the interaction between perovskite and metal atoms, introducing a thin buffer layer to separate them without hindering the charge transport has been reported as a successful strategy ${ }^{19,20}$. However, materials from the perovskite or the electrode tend to penetrate that buffer layer on a long timescale because achieving a thin but uniform and compact coverage on a large area with buffer layers that are usually formed by solution-processable small molecules or polymers is hard ${ }^{21}$, calling for an increased intrinsic chemical stability of rear electrodes for PSCs.

Copper $(\mathrm{Cu})$ is a potential candidate due to its relative inertness to migrated perovskite components and has been widely used in inverted PSCs ${ }^{22}$. However, its work function (WF) of $4.65 \mathrm{eV}$ limits its application in efficient regular PSCs, which usually use 2,2',7,7'- 
tetrakis( $N, N$-dip-methoxyphenylamine)-9,9'-spirobifluorene (spiro-OMeTAD) or poly[bis(4-phenyl)(2,4,6-trimethylphenyl)amine] (PTAA) with a highest occupied molecular orbital (HOMO) of around $-5.2 \mathrm{eV}^{23}$. In addition, $\mathrm{Cu}$ can be oxidized by oxygen and moisture to generate products such as $\mathrm{Cu}_{2}(\mathrm{OH})_{2} \mathrm{CO}_{3}$ and $\mathrm{Cu}$ atoms were reported to diffuse into perovskite at $85^{\circ} \mathrm{C}^{24}$. Besides metal electrodes, intrinsically stable carbon electrodes have also been applied to PSCs and 9000 hours of operational stability at the maximum power point tracking (MPPT) and $55^{\circ} \mathrm{C}$ was recently reported with no obvious change in the power conversion efficiency (PCE) ${ }^{25}$. However, big challenges exist for them to obtain high efficiencies because of the severe potential losses ${ }^{26}$. Therefore, it is still an open issue to develop a low-cost rear electrode with a tunable WF that combines chemical stability and high efficiency.

Herein, we report a composite electrode that consists of (i) Cu-nickel (Ni) alloy and (ii) in situ grown bifacial graphene. The microalloying of $\mathrm{Cu}$ with $\mathrm{Ni}(125: 1 / \mathrm{v}: \mathrm{v})$ improves its electrochemical stability without compromising the electrical properties and makes it possible to tune the WF of $\mathrm{Cu}$ to fit the requirements of regular PSCs by simply varying the content of Ni. Moreover, $\mathrm{Cu}-\mathrm{Ni}$ alloy is an ideal substrate for preparing high-quality graphene on both sides by chemical vapor deposition (CVD), which acts as natural barrier and substantially strengthens the stability of $\mathrm{Cu}-\mathrm{Ni}$ alloy because the outer graphene can block the penetration of water and oxygen while the inner graphene can suppress the migration of perovskite components or metal atoms caused by light and heat. The 
composite electrode is hot pressed on the semi-device with the assistance of a thermoplastic copolymer, which ensures the efficient charge collection at the interface of semidevice/electrode. As a result, a PCE of $24.34 \%$ was achieved for the regular device using graphene/Cu-Ni/graphene composite as rear electrode (CNG device) with an aperture area of $0.09 \mathrm{~cm}^{2}$, comparable to that of the device using Ag electrode. After the optimization of the thermoplastic copolymer with conductive graphene nanoflake (GN), we obtained a PCE of over $20.76 \%$ for $\mathrm{CNG}$ device with an aperture area of $1.02 \mathrm{~cm}^{2}$. The CNG devices without encapsulation retained $97 \%$ of their initial PCEs after the aging test of heating at $85^{\circ} \mathrm{C}$ with relative humidity (RH) of $c a .85 \%$ for 1440 hours and the encapsulated devices maintained $95 \%$ of their initial PCEs after operating at the MPPT under continuous 1 sun illumination for 5000 hours.

\section{Fabrication and characterization of CNG electrodes}

The fabrication process of CNG composite electrode and the assembly of the whole device (Extended Data Fig. 1) are detailed in Methods. The thickness of the sputtered Ni before annealing is set at $200 \mathrm{~nm}$ to obtain a WF for $\mathrm{Cu}-\mathrm{Ni}$ that is compatible with the HOMOs of spiro-OMeTAD or PTAA (Extended Data Fig. 2, A to D). The cross-sectional scanning electron microscopy (SEM) of $\mathrm{Cu}-\mathrm{Ni}$ and the corresponding energy dispersive spectroscopy (EDS) elemental mapping images confirm the uniform distribution of $\mathrm{Ni}$ in $\mathrm{Cu}$ foil after thermal annealing under reducing atmosphere (Extended Data Fig. 2, E to G). This process also smoothens the surface of the substrate, thereby preparing it for in situ 
growth of graphene, as demonstrated by the atomic force microscopy (AFM) (Extended Data Fig. 2, H).

A uniform but thin layer of graphene is required here to meet the demand of being an efficient barrier without introducing extra defects or hindering the carrier transport. ${ }^{27} \mathrm{We}$ focus on the characterization of one side since the quality of graphene on both sides should be identical in a CVD method. Using $\mathrm{CH}_{4}$ as the carbon source, with respective flow rates of 5, 10 and 15 standard cubic centimeter per minute (scm), diluted in $100 \mathrm{sccm} \mathrm{Ar} / \mathrm{H}_{2}$, we arm both sides of the $\mathrm{Cu}-\mathrm{Ni}$ alloy with graphene with varying number of layers and quality, denoted as CNG-5, CNG-10 and CNG-15, respectively. Their optical microscope $(\mathrm{OM})$ images are provided in Fig. 1, A to C. Obviously, due to the difference in the content of carbon source, the graphene on CNG-5 and CNG-15 form a non-uniform monolayer and coexisting monolayer and bilayer, respectively. In contrast, a uniform monolayer graphene is observed on CNG-10. To further determine the quality and layer numbers of graphene, Raman spectra are measured for the three samples. The full width at half maximum (FWHM) for 2D peak at $c a .2680 \mathrm{~cm}^{-1}$ are shown in Fig. 1, D to F; the graphene of CNG10 exhibits the most uniform distribution of FWHM for 2D peak with an average value of below $45 \mathrm{~cm}^{-1}$. Coupled with the intensity ratios of 2D peak and G peak at $c a .1584 \mathrm{~cm}^{-1}$ $\left(\mathrm{I}_{2 \mathrm{D}} / \mathrm{I}_{\mathrm{G}}\right)$, as shown in Fig. $1, \mathrm{G}$ to $\mathrm{I}$, the layer numbers of graphene on CNG-5, CNG-10 and CNG-15 can be deduced ${ }^{28}$. The graphene of CNG-5 contains regions of $\mathrm{I}_{2 \mathrm{D}} / \mathrm{I}_{\mathrm{G}}>2.5$, which represents discontinuous monolayer graphene film and is consistent with the OM image in 
Fig. 1A. The $\mathrm{I}_{2 \mathrm{D}} / \mathrm{I}_{\mathrm{G}}$ for $\mathrm{CNG}-10$ almost locates between 1.5 and 2.5 , indicating the formation of monolayer graphene. Further increase in the content of $\mathrm{CH}_{4}$ leads to blue regions for CNG-15 $\left(0.8<\mathrm{I}_{2 \mathrm{D}} / \mathrm{I}_{\mathrm{G}}<1.2\right)$, which is indicative of the formation of non-uniform bilayer and agrees well with the FWHM of $60 \mathrm{~cm}^{-1}$ in Fig. 1F. Incomplete coverage may weaken the function of being the barrier for water, oxygen and migrated components, whereas overlapped graphene not only enlarges the defect density at this interface (Extended Data Fig. 3, A to C) but also increases the series resistance $\left(R_{\mathrm{S}}\right)$ of PSCs. Therefore, CNG-10 is expected to be the most suitable composite electrode among the three samples.

\section{Assembly and performance of CNG devices}

Before the assembly of an integral device, the effect of graphene on the WFs of Cu-Ni alloy is measured by ultraviolet photoelectron spectroscopy (UPS). As shown in Extended Data Fig. 4, A to D, the WFs of CNG-5, CNG-10 and CNG-15 composite electrodes are 5.15, 5.11 and $4.99 \mathrm{eV}$, respectively, which are also compatible with the HOMOs of the commonly used HTMs in regular PSCs. The integral devices are fabricated by hot pressing CNG electrodes on the semi-device with the structure of fluorine-doped tin oxide (FTO)/SnO $/ \mathrm{Sn}_{2}$ perovskite/HTM. A thin adhesive layer of thermoplastic ethylene vinyl acetate (EVA) copolymer is employed at the interface to assist the combination of HTMs and CNG electrodes and to fill the possible gaps left after hot pressing, which is beneficial for realizing efficient carrier tunneling and thereby the enhanced ohmic contact ${ }^{29}$. The 
temperature of hot pressing is set at $130^{\circ} \mathrm{C}$, which is a conventional value for EVA-based materials. In addition, the pressure and time are optimized to be $0.3 \mathrm{MPa}$ and 60 seconds, respectively, after the measurement of the resistance of $\mathrm{CNG}$ electrodes/EVA/spiroOMeTAD/FTO (Extended Data Fig. 4, E and F).

Fig. 2A shows the cross-sectional SEM image of a CNG device; EVA is too thin to be distinguishable so that it can realize efficient carrier tunneling. The current density-voltage $(J-V)$ curves of PSCs using CNG-5, CNG-10, CNG-15 and Ag electrodes (CNG-5, CNG10, CNG-15, Ag device) under forward scan are presented in Fig. 2B. The CNG-10 device obtained a PCE of $24.34 \%$ with an aperture area of $0.09 \mathrm{~cm}^{2}$, which is comparable with that of the Ag device (best PCE $=24.65 \%$ ). The detailed photovoltaic parameters of Fig. 2B are summarized in Extended Data Table 1. The inferior performance of CNG-5 and CNG-15 devices can be attributed to the lower quality of graphene, leading to the charge accumulation at the HTM/electrode interface. This effect can be verified by capacitancevoltage $(C-V)$ measurements via searching the characteristic peaks in capacitance at a specific region of bias under light ${ }^{30}$. As shown in Extended Data Fig. 5, A to D, the $C-V$ curve of the CNG-10 device shows no obvious peaks, indicating the fast charge transport in the device, whereas the CNG-5 device shows a peak at $c a$. $-1.1 \mathrm{~V}$ and the CNG-15 device shows peaks at both $c a$. $-0.3 \mathrm{~V}$ and $-1.1 \mathrm{~V}$, respectively, indicating the charge accumulation in those devices. Twenty devices of each batch were fabricated and the histogram of average PCE values are shown in Extended Data Fig. 6; the CNG-10 devices exhibit a 
narrower distribution of PCE compared with other CNG devices and thereby a higher reproducibility due to the uniform and high-quality graphene layer, as demonstrated in Fig. 1.

We further fabricated CNG device with an aperture area of $1.02 \mathrm{~cm}^{2}$. However, a much lower PCE of $15.43 \%$ was achieved (Extended Data Fig. 7, A), probably due to the nonuniformity of hot pressing, which may cause larger gaps at the interface beyond the thickness of EVA. In this case, we slowed down the rotation speed of EVA from 6000 to 5500 and 5000 r.p.m and the $R_{\mathrm{S}}$ of the corresponding devices first reduces and then suddenly increases to a much higher value (Extended Data Fig. 7, B), which means that the choice of 5000 r.p.m leads to the formation of an insulating layer too thick to allow charge tunneling. To allow for higher EVA thickness in localized areas with larger gaps, we mitigated resistive losses via addition of GN in EVA to boost the conductivity. The carbonyl group on the branch chain of EVA can interact with GN via Van der Waals force, as confirmed by the small blue shift $(c a .0 .33 \mathrm{eV})$ of $\mathrm{C}=\mathrm{O}$ peak measured by $\mathrm{x}$-ray photoelectron spectroscopy (XPS) in Extended Data Fig. 7, C, which helps the formation of conductive network of GN in EVA matrix ${ }^{31}$. As is shown in Extended Data Fig. 7, D, the volume resistance of EVA goes through a sudden drop when the mass ratio of GN reaches $1.6 \mathrm{wt} \%$ and further increase to $2.4 \mathrm{wt} \%$ barely improves the conductivity, indicating the formation of a stable conductive network. The $J-V$ curves of the devices with $0.8 \mathrm{wt} \%, 1.6 \mathrm{wt} \%$ and $2.4 \mathrm{wt} \% \mathrm{GN}$ in EVA are shown in Fig. $2 \mathrm{C}(0.8 \%-, 1.6 \%$ - and $2.4 \%$ - 
device). Obviously, the PCE of the device is greatly improved to $20.76 \%$ when the network is constructed (1.6\%-device) and the corresponding incident photon-electron conversion efficiency (IPCE) is provided in Extended Data Fig. 7, E, showing a minimal mismatch with the $J_{\mathrm{SC}}$ from the $J-V$ scan $(<3 \%)$. In addition, no obvious hysteresis was observed (Extended Data Fig. 7, F). However, a drop in the optoelectronic performance is found for $2.4 \%$-device, especially in the open-circuit voltage and the fill factor. To disclose the reason, we measured the transient photovoltage (TPV) decay to analyze the charge carrier dynamics in the devices (Fig. 2D). The faster decay of TPV for $2.4 \%$-device suggests a shorter charge carrier lifetime than that for $1.6 \%$ device, which may be related to the aggregation of $\mathrm{GN}^{32}$. The distribution of GN in EVA is characterized by Raman spectra (Fig. 2E and F); apparent aggregation of GN represented by the red regions is found in EVA with $2.4 \mathrm{wt} \% \mathrm{GN}$, which may bring about higher concentration of defects that cause extra non-radiative losses at the interface. It should be noted that a variety of conductive additives can be chosen to boost the conductivity of the copolymer. However, to guarantee the stability of the interface, stable materials with good dispersity will be the priority selection.

\section{Stabilizing mechanism of CNG electrode}

To reveal the stabilizing mechanism of $\mathrm{CNG}$, we first studied their resistance to water and oxygen. As shown in Extended Data Fig. 8, A to E, the contact angle with water in air rises from $74.9^{\circ}$ for $\mathrm{Ag}$ electrode to $102^{\circ}$ for $\mathrm{CNG}-10$, which should be beneficial for 
repelling water. Even if water is dropped and stays at the surface of CNG-10 for 24 hours, the color of perovskite remains black, while the perovskite under $\mathrm{Ag}$ turns yellow (Extended Data Fig. 8, F and G). To exclude the effect of electrode thickness, the permeation rates of water and oxygen for CNG-10 electrodes are measured and drop to $3.32 \%$ and $5.38 \%$ of the initial values for $\mathrm{Cu}-\mathrm{Ni}$ alloy after equipped with air-tight and hydrophobic graphene (Extended Data Fig. 9, A and B). The reduced permeability meets the requirements for encapsulation ${ }^{33}$. To study this encapsulation effect of $\mathrm{CNG}$ electrodes on devices, in Fig. 3A, we conducted the gas chromatography-mass spectrometry (GC-MS) to compare the volatile products escaping from $\mathrm{Ag}$ and $\mathrm{CNG}-10$ devices after aging tests at $85^{\circ} \mathrm{C}$ and $85 \% \mathrm{RH}$ in the air for 500 hours ${ }^{34}$. As a result, barely no volatile products are found for $\mathrm{CNG}$ device, except for a small quantity of $\mathrm{NH}_{3}$ and $\mathrm{NO}$. By contrast, a variety of products are detected for $\mathrm{Ag}$ device, including the additive 4-tert-butylpyridine from spiro-OMeTAD. The GC-MS results demonstrate superior damp heat stability of CNG device. To investigate the electrochemical corrosion of CNG electrodes, Tafel curves for $\mathrm{Cu}, \mathrm{Cu}-\mathrm{Ni}$ and $\mathrm{CNG}-10$ are measured (Fig. 3B). Compared with $\mathrm{Cu}$, the corrosion current is lower at the anodic section for $\mathrm{Cu}-\mathrm{Ni}$, implying slower corrosion rate due to the microalloying with Ni. For the sample of CNG-10, the self-corrosion potential ( $\left.E_{\text {corr }}\right)$ positively shifts from $-0.34 \mathrm{~V}(\mathrm{Cu}$ and $\mathrm{Cu}-\mathrm{Ni})$ to $-0.29 \mathrm{~V}$, representing much higher resistance to chemical corrosion, which is owed to not only the blocking of water and oxygen, but also the decrease in the migration rate of ionic species that can trigger oxidation and reduction ${ }^{35}$. 
The effect of CNG-10 electrode on the suppression of migrated ions and metal atoms in the devices is further demonstrated. After removing the package and peeling off the electrodes of the devices that were aged under MPPT for 1000 hours, XPS measurement reveals an I- signal much lower inside CNG-10 than that inside Ag (Extended Data Fig. 10, $\mathrm{A}$ and $\mathrm{B}$ ), which preserves the morphologies of spiro-OMeTAD and perovskite, as shown in Extended Data Fig. 10, C and D. The spatial distribution of $\mathrm{I}^{-}, \mathrm{Ag}^{-}$and $\mathrm{Cu}^{-}$for the aged $\mathrm{Ag}$ and $\mathrm{CNG}$ devices are analyzed by time-of-flight secondary ion mass spectroscopy (ToF-SIMS, Extended Data Fig. 10, E and F). Obviously, the I- (Fig. 3C) and $\mathrm{Ag}^{-}$(Fig. 3E) in the aged Ag device have migrated over the whole depth of the device while $\mathrm{I}^{-}$(Fig. 3D) and $\mathrm{Cu}^{-}$(Fig. 3F) in the aged CNG-10 device are almost confined to their original layers.

\section{Stabilizing effect of CNG electrode on devices}

CNG-10 devices without encapsulation retained $97 \%$ of their initial efficiency after the aging test of heating at $85^{\circ} \mathrm{C}$ with $\mathrm{ca} .85 \% \mathrm{RH}$ for 1440 hours, whereas the PCEs of the control devices dropped to $56.5 \%$ of their initial PCEs after 936 hours (Fig. 4A). For the operational stability test, another control sample using $\mathrm{Cu}-\mathrm{Ni}$ alloy with bifacial sprayed graphene as the electrode (SG device) was tested. All the encapsulated devices were measured under MPPT with continuous 1 sun illumination; the CNG-10 devices retained 95\% of their initial PCEs after 5000 hours with a small deviation across five individual cells, while the PCEs of the SG and Au devices dropped to 59\% and 30\% of their initial PCEs after 2500 and 1250 hours, respectively, with much larger deviations (Fig. 4B). The 
inferior performance of SG device may be ascribed to numerous pores in overlapped graphene.

\section{Online content}

Any methods, additional references, Nature Research reporting summaries, source data, statements of data availability and associated accession codes are available.

\section{References and Notes}

1 Kojima, A., Teshima, K., Shirai, Y. \& Miyasaka, T. Organometal halide perovskites as visible-light sensitizers for photovoltaic cells. J. Am. Chem. Soc. 131, 6050-6051, doi:10.1021/ja809598r (2009).

2 Kim, H. S. et al. Lead iodide perovskite sensitized all-solid-state submicron thin film mesoscopic solar cell with efficiency exceeding 9\%. Sci. Rep-Uk 2, 591, doi:10.1038/srep00591 (2012).

3 Jeon, N. J. et al. Compositional engineering of perovskite materials for highperformance solar cells. Nature 517, 476-480, doi:10.1038/nature14133 (2015).

4 Li, J. et al. Highly efficient thermally co-evaporated perovskite solar cells and minimodules. Joule 4, 1035-1053, doi:10.1016/j.joule.2020.03.005 (2020).

5 Yoo, J. J. et al. Efficient perovskite solar cells via improved carrier management. Nature 590, 587-593, doi:10.1038/s41586-021-03285-w (2021).

6 Cai, M. et al. Cost-performance analysis of perovskite solar modules. Adv. Sci. 4, 1600269, doi:10.1002/advs.201600269 (2017). 
7 Boyd, C. C., Cheacharoen, R., Leijtens, T. \& McGehee, M. D. Understanding degradation mechanisms and improving stability of perovskite photovoltaics. Chem. Rev. 119, 3418-3451, doi:10.1021/acs.chemrev.8b00336 (2019).

8 Wang, Q., Phung, N., Di Girolamo, D., Vivo, P. \& Abate, A. Enhancement in lifespan of halide perovskite solar cells. Energy Environ. Sci. 12, 865-886, doi:10.1039/c8ee02852d (2019).

9 Bai, S. et al. Planar perovskite solar cells with long-term stability using ionic liquid additives. Nature 571, 245-250, doi:10.1038/s41586-019-1357-2 (2019).

10 Kong, J. et al. $\mathrm{CO}_{2}$ doping of organic interlayers for perovskite solar cells. Nature 594, 51-56, doi:10.1038/s41586-021-03518-y (2021).

11 Wang, Y. B. et al. Stabilizing heterostructures of soft perovskite semiconductors. Science 365, 687-691, doi:10.1126/science.aax8018 (2019).

12 Yang, S. et al. Stabilizing halide perovskite surfaces for solar cell operation with wide-bandgap lead oxysalts. Science 365, 473-478, doi:10.1126/science.aax3294 (2019).

13 Xiao, J.-W. et al. Contact engineering: electrode materials for highly efficient and stable perovskite solar cells. Sol. $\operatorname{Rrl}$ 1, 1700082, doi:10.1002/solr.201700082 (2017).

14 Li, J. W., Dong, Q. S., Li, N. \& Wang, L. D. Direct evidence of ion diffusion for the silver-electrode-induced thermal degradation of inverted perovskite solar cells. Adv. Energy Mater. 7, 1602922, doi:10.1002/aenm.201602922 (2017). 
15 Kato, Y. et al. Silver iodide formation in methyl ammonium lead iodide perovskite solar cells with silver top electrodes. Adv. Mater. Interfaces 2, 1500195. doi:10.1002/admi.201500195 (2019)

16 Xiong, J. et al. Interface degradation of perovskite solar cells and its modification using an annealing-free $\mathrm{TiO}_{2}$ NPs layer. Org. Electron. 30, 30-35, doi:10.1016/j.orgel.2015.12.010 (2016).

17 Lin, X. S. et al. Efficiency progress of inverted perovskite solar cells. Energy Environ. Sci. 13, 3823-3847, doi:10.1039/d0ee02017f (2020).

18 Domanski, K. et al. Not all that glitters is gold: metal-migration-induced degradation in perovskite solar cells. ACS Nano 10, 6306-6314, doi:10.1021/acsnano.6b02613 (2016).

19 Hou, Y. et al. A generic interface to reduce the efficiency-stability-cost gap of perovskite solar cells. Science 358, 1192-1197, doi:10.1126/science.aao5561 (2017).

20 Arora, N. et al. Perovskite solar cells with $\mathrm{CuSCN}$ hole extraction layers yield stabilized efficiencies greater than 20\%. Science 358, 768-771, doi:10.1126/science.aam5655 (2017).

21 Peng, J. et al. Nanoscale localized contacts for high fill factors in polymerpassivated perovskite solar cells. Science 371, 390-395, doi:10.1126/science.abb8687 (2021).

22 Zhao, J. J. et al. Is $\mathrm{Cu}$ a stable electrode material in hybrid perovskite solar cells for 15 
a 30-year lifetime? Energy Environ. Sci. 9, 3650-3656, doi:10.1039/c6ee02980a (2016).

23 Calio, L., Kazim, S., Graetzel, M. \& Ahmad, S. Hole-transport materials for perovskite solar cells. Angew. Chem. Int. Ed. 55, 14522-14545, doi:10.1002/anie.201601757 (2016).

24 Li, X. D. et al. Chemical anti-corrosion strategy for stable inverted perovskite solar cells. Sci. Adv. 6, eabd1580, doi:10.1126/sciadv.abd1580 (2020).

25 Mei, A. Y. et al. Stabilizing perovskite solar cells to IEC61215:2016 standards with over 9,000-h operational tracking. Joule 4, 2646-2660, doi:10.1016/j.joule.2020.09.010 (2020).

26 Bogachuk, D. et al. Low-temperature carbon-based electrodes in perovskite solar cells. Energy Environ. Sci. 13, 3880-3916, doi:10.1039/D0EE02175J (2020).

$27 \mathrm{Su}, \mathrm{H}$. Z. et al. The application of graphene derivatives in perovskite solar cells. Small Methods 4, 2000507, doi:10.1002/smtd.202000507 (2020).

28 Nguyen, V. L. et al. Layer-controlled single-crystalline graphene film with stacking order via Cu-Si alloy formation. Nat. Nanotech. 15, 861-867, doi:10.1038/s41565020-0743-0 (2020).

29 Huang, Z. Q. et al. Water-resistant and flexible perovskite solar cells via a glued interfacial layer. Adv. Funct. Mater. 29, 1902629, doi:10.1002/adfm.201902629 (2019).

30 Chen, C. L. et al. Effect of BCP buffer layer on eliminating charge accumulation 16 
for high performance of inverted perovskite solar cells. RSC Adv. 7, 35819-35826, doi:10.1039/c7ra06365b (2017).

$31 \mathrm{Wu}, \mathrm{C}$. et al. Highly conductive nanocomposites with three-dimensional, compactly interconnected graphene networks via a self-assembly process. $A d v$. Funct. Mater. 23, 506-513, doi:10.1002/adfm.201201231 (2013).

$32 \mathrm{Li}, \mathrm{Y}$. et al. Multifunctional fullerene derivative for interface engineering in perovskite solar cells. J. Am. Chem. Soc. 137, 15540-15547, doi:10.1021/jacs.5b10614 (2015).

33 Uddin, A., Upama, M. B., Yi, H. M. \& Duan, L. P. Encapsulation of organic and perovskite solar cells: A Review. Coatings 9, 65-81, doi:10.3390/coatings9020065 (2019).

34 Shi, L. et al. Gas chromatography-mass spectrometry analyses of encapsulated stable perovskite solar cells. Science 368, eaba2412, doi:10.1126/science.aba2412 (2020).

35 Metikos-Hukovic, M., Babic, R. \& Paic, I. Copper corrosion at various pH values with and without the inhibitor. J. Appl. Electrochem. 30, 617-624, doi:10.1023/a:1003956102631 (2000).

Acknowledgments: We thank Z. Bao and Y. Han from the Instrumental Analysis Center of Shanghai Jiao Tong University (China) for assistance with SEM measurements. J. Ding from the Instrumental Analysis Center of Shanghai Jiao Tong University (China) for 
assistance with ToF-SIMS measurements. X. Ding and N. Zhang from the Instrumental Analysis Center of Shanghai Jiao Tong University (China) for assistance with XPS and UPS measurements. R. Wang from the Instrumental Analysis Center of Shanghai Jiao Tong University (China) and Kai Jiang from Engineering Research Center for Nan photonics and Advanced Instrument, Ministry of Education, School of Physics and Electronic Science, East China Normal University (China) for assistance with Raman spectra measurements. X. Liu and Y. Liu from the Instrumental Analysis Center of Shanghai Jiao Tong University (China) for assistance with GC-MS measurements. Y. Liu and Y. Li from the Instrumental Analysis Center of Shanghai Jiao Tong University (China) for assistance with static contact angle measurements. Funding: National Natural Science Foundation of China grant 11834011, National Natural Science Foundation of China grant 12074245, Shanghai Sailing Program grant 21YF1421600, National Key R\&D Program of China grant 2020YFB1506400.

Author contributions: Conceive of the work: X.L., B.Y.W., L.H.; Fabricate solar cells: X.L., H.S.; Conduct the SEM, AFM, EIS, $C-V$, TPV, $J-V$, and ToF-SIMS measurements: X.L.; Prepare the $\mathrm{Cu}-\mathrm{Ni}$ alloy, graphene and synthesize the EVA-based adhesive: H.S., S.H., Y.S.; Perform the AFM, XPS and UPS measurements: H.S., S.H., Y.S.; Assist with the analysis of ToF-SIMS and XPS: X.Y., Q.H.; Assist with the analysis of the Tafel polarization curves: J. F.; Assist with measurement of TPV: Z.Q.; Assist with the analysis 
of GC-MS: Z.Y.W.; Write the first draft of the manuscript: X.L.; Revise the manuscript:

X.L., M.G., B.Y.W., L.H.. All authors analyzed the data and reviewed the manuscript.

Competing interests: None declared.

\section{Additional information:}

Supplementary information is available for this paper.

Reprints and permissions information is available at www.nature.com/reprints.

Correspondence and requests for materials should be addressed to Y.B. Wang or L.Y.

Han. 

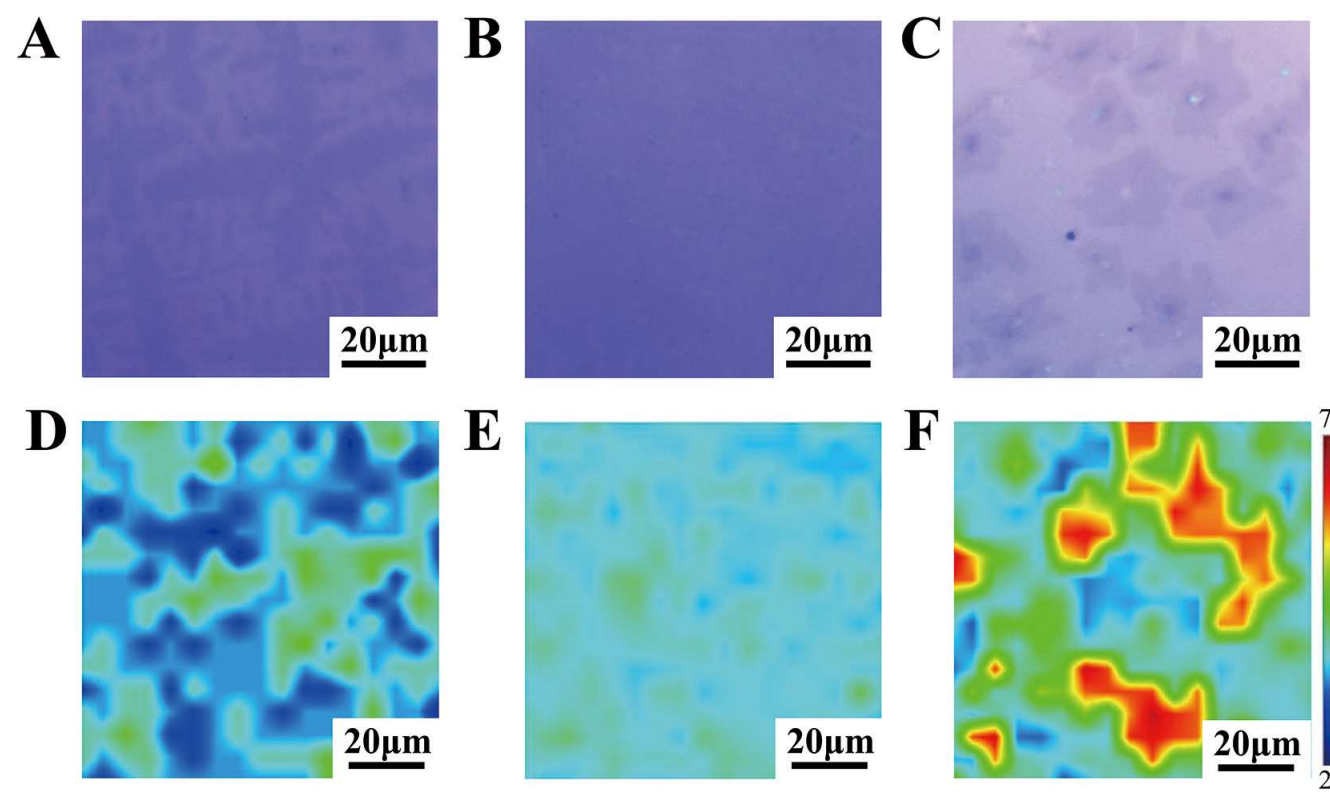

$\mathbf{E}$
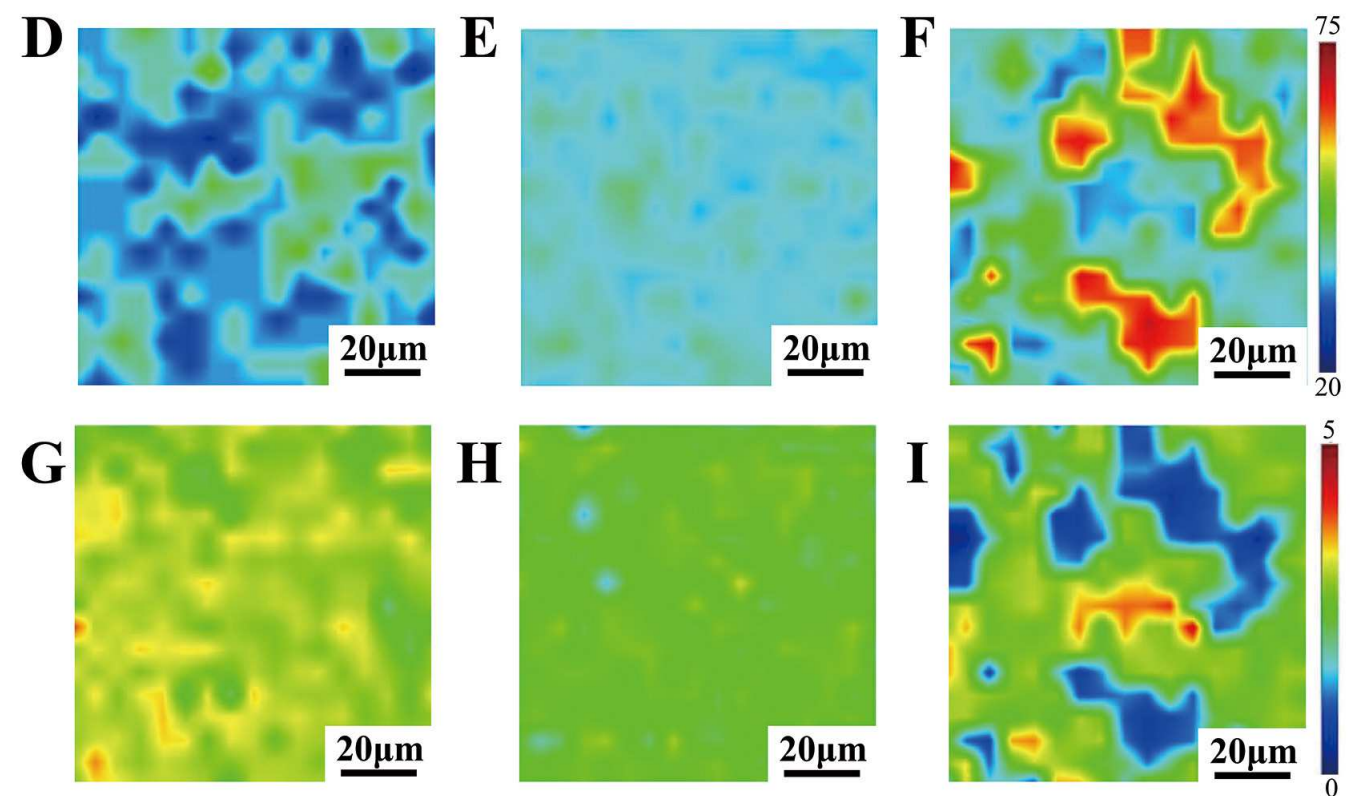

Fig. 1. The quality and layer number of graphene of CNG composite electrodes characterized by OM and Raman spectra. (A to C) OM images, (D to F) Raman mapping of 2D FWHM and (G to I) $\mathrm{I}_{2 \mathrm{D}} / \mathrm{I}_{\mathrm{G}}$ of graphene on CNG-5, CNG-10 and CNG-15. The transfer method of graphene used for the measurement of OM and Raman spectra is based on previous work ${ }^{28}$. 

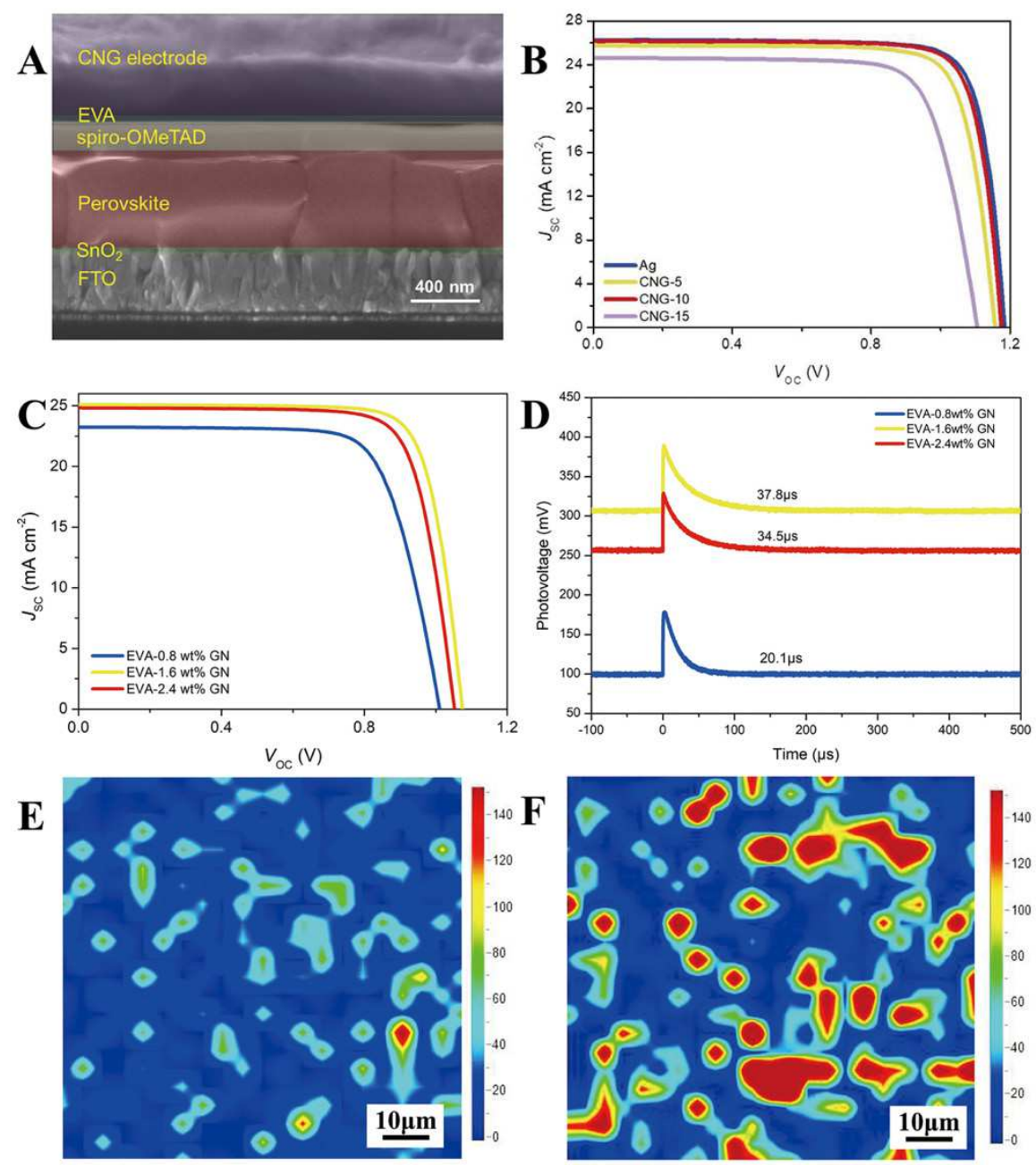

Fig. 2. The structure and performance of PSCs with aperture areas of 0.09 and $1.02 \mathrm{~cm}^{2}$. (A) Cross-sectional SEM image of CNG-10 device. (B) $J-V$ curves of CNG and Ag devices with an aperture area of $0.09 \mathrm{~cm}^{2}$ under forward scan. (C) $J-V$ curves and (D) corresponding TPV results of $1.02 \mathrm{~cm}^{2} \mathrm{CNG}$ devices with different modified adhesive layers in the mass ratio of GN in EVA. Raman mapping of G peak for (E) $1.6 \mathrm{wt} \%$ and (F) $2.4 \mathrm{wt} \% \mathrm{GN}$ in EVA, respectively. 

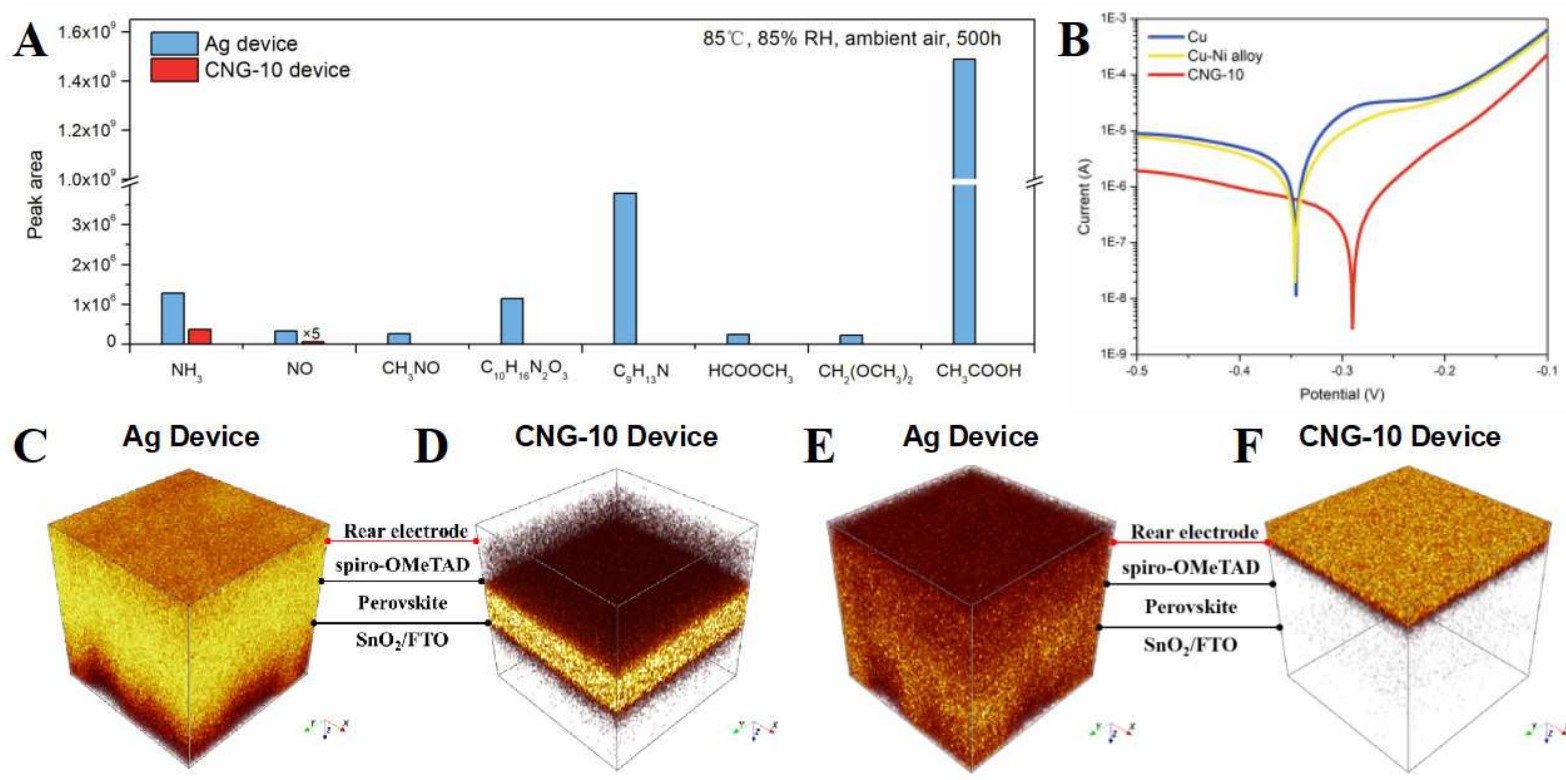

F CNG-10 Device

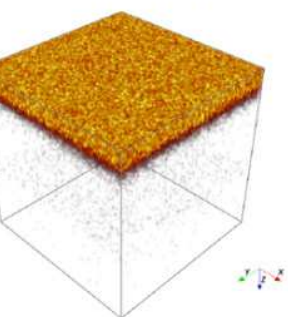

Figure 3. The stabilizing mechanism of CNG electrodes. (A) GC-MS peak areas of products for the aged Ag and CNG-10 devices. (B) Tafel curves for $\mathrm{Cu}, \mathrm{Cu}-\mathrm{Ni}$ and $\mathrm{CNG}-10$ electrodes in $\mathrm{NaCl}$ solution (3.5 $\mathrm{wt}^{\%} \%$ ). The spatial distribution of $\mathrm{I}^{-}$in the aged (C) $\mathrm{Ag}$ and (D) CNG devices, respectively. The spatial distribution of (E) $\mathrm{Ag}^{-}$and $(\mathrm{F}) \mathrm{Cu}^{-}$in the aged $\mathrm{Ag}$ and $\mathrm{CNG}$ devices, respectively. 

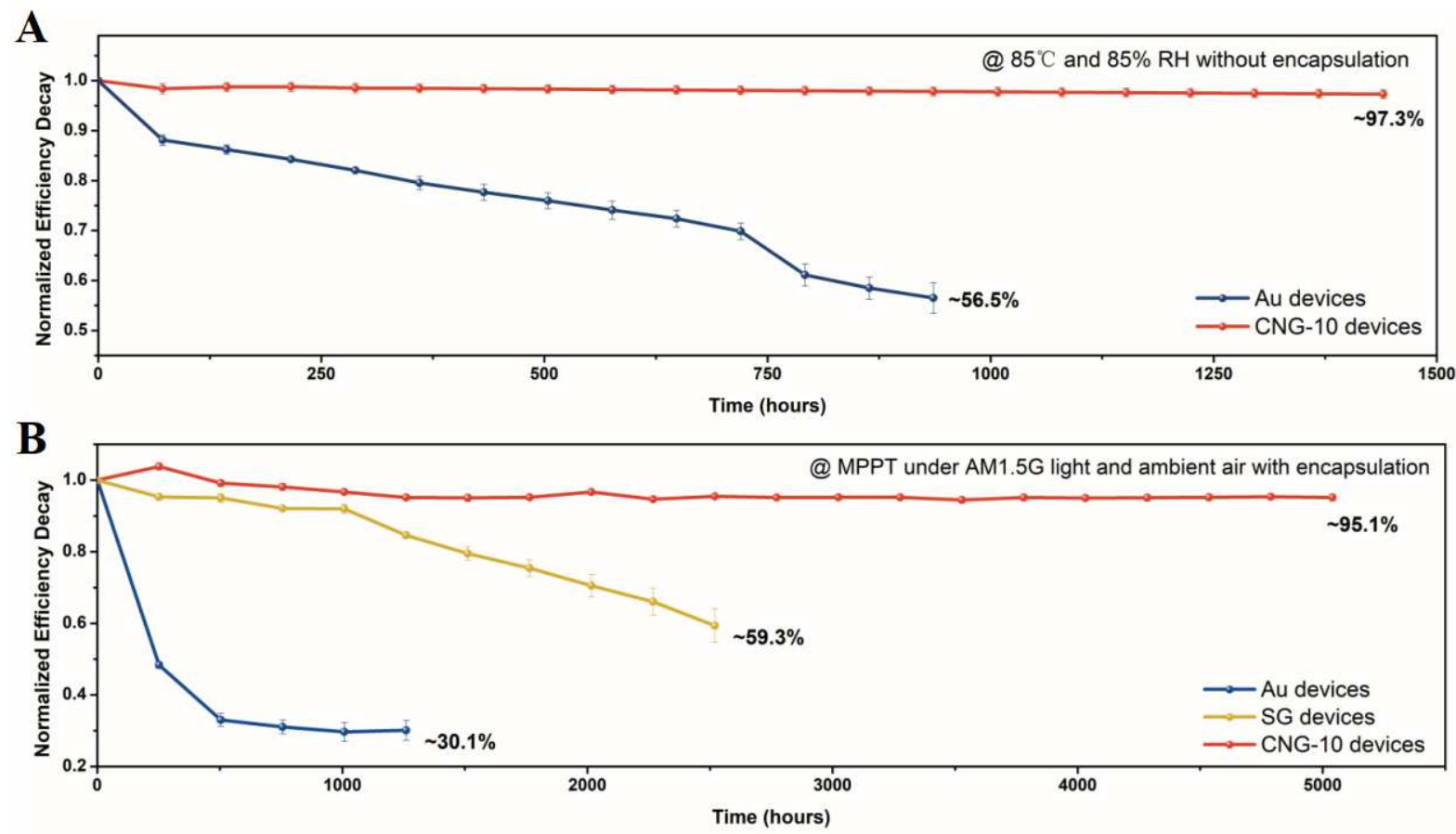

Figure 4. The stabilizing effect of CNG electrodes on devices. (A) The damp heat stability of the $\mathrm{Au}$ and CNG-10 devices without encapsulation. (B) The operational stability of the encapsulated Au, SG and CNG-10 devices. The error bars denote standard deviations for five individual devices. 


\section{Methods}

Materials. All the chemicals were used without further purification, including (1) $\mathrm{SnO}_{2}$ electron transport material (ETM): dispersing $\mathrm{SnO}_{2}, 15 \%$ in $\mathrm{H}_{2} \mathrm{O}$ colloidal dispersion (Alfa Aesar), deionized water (Sigma Aldrich); (2) perovskite precursor: $\mathrm{CH}\left(\mathrm{NH}_{2}\right)_{2} \mathrm{I}$ (FAI, 98\%, TCI), $\mathrm{CH}_{3} \mathrm{NH}_{3} \mathrm{Cl}$ (MACl, 98\%, TCI), $\mathrm{PbI}_{2}$ (99.99\%, TCI), dimethylformamide (DMF, 99.8\%, Sigma Aldrich), dimethyl sulfoxide (DMSO, 99.9\%, Sigma Aldrich), isopropanol (IPA, Sigma Aldrich); (3) spiro-OMeTAD HTM: spiro-OMeTAD (99.8\%, Ningbo Borun New Material Technology Co., LTD.), 4-tert-butylpyridine (tBP, Xi'an Polymer Light Technology), bis(trifluoromethane)sulfonimide lithium salt (Li-TFSI, 99.95\%, Sigma Aldrich), acetonitrile (99.8\%, Sigma Aldrich), chlorobenzene (CB, 99.8\%, Sigma Aldrich), PTAA (Sigma Aldrich), toluene (99.8\%, Sigma Aldrich); (4) Electrode: Ag, Au (99.999\%, Beijing Dream Material Technology Co. LTD.), Cu foil (99.8\%, Alfa Aesar), Ni target (99.995\%, Beijing ZhongNuo Advanced Material Technology Co., LTD.), EVA (with 40\% ethenyl acetate, Sigma Aldrich), GN (Alfa Aesar) for adhesive, xylene (99\%, Aladdin), graphene for SG device (99\%, Alfa Aesar). Chlorinated graphene oxide (Cl-GO) is synthesized according to previous work ${ }^{11}$.

Synthesis of EVA-based adhesives. Different amount of GN from 0 to $6 \mathrm{mg}$ were added into $10 \mathrm{~mL}$ xylene and sonicated for 1 hour to form a homogeneous $\mathrm{GN}$ dispersion. $0.25 \mathrm{~g}$ of EVA was then added into the dispersions. The samples were placed on a drying oven at $80^{\circ} \mathrm{C}$ to swell for 1 hour. The swelled sample was further stirred for 10 hours to form homogeneous EVA adhesive and EVA-GN adhesive. 
Fabrication of CNG and SG electrodes. For the fabrication of CNG electrodes, the $\mathrm{Cu}$ foil was first chemically polished on both sides and sonicated with detergent, deionized water, ethanol, acetone and IPA for 15 minutes, respectively. Ni with respective thicknesses of 100, 200 and $300 \mathrm{~nm}$ were then sputtered on the $\mathrm{Cu}$ foil using the magnetron sputtering method followed by thermal annealing under $100 \mathrm{sccm} \mathrm{Ar} / \mathrm{H}_{2}$ reducing atmosphere at $1000^{\circ} \mathrm{C}$ for 1 hour to form uniform $\mathrm{Cu}-\mathrm{Ni}$ alloys. By employing 5, 10 and $15 \mathrm{sccm}$ of $\mathrm{CH}_{4}$ diluted in $100 \mathrm{sccm} \mathrm{Ar} / \mathrm{H}_{2}$ as carbon source at $1000^{\circ} \mathrm{C}$ for 30 minutes, both-sides of $\mathrm{Cu}-\mathrm{Ni}$ alloy were protected by graphene with varying number of layers and quality, denoted as CNG-5, CNG-10 and CNG-15, respectively. For the fabrication of SG electrode, $20 \mathrm{mg}$ graphene was dispersed into $5 \mathrm{~mL}$ IPA through ball-milling for 12 hours to obtain a homogeneous dispersion. Then, $150 \mu \mathrm{L}$ dispersion was sprayed onto both sides of $\mathrm{Cu}-\mathrm{Ni}$ alloy followed by annealing at $85^{\circ} \mathrm{C}^{36}$.

Fabrication of PSCs with different electrodes. The FTO substrates were etched with zinc powder and $6 \mathrm{M} \mathrm{HCl}$ for 15 seconds to obtain patterned substrates, followed by sonication with detergent, deionized water, ethanol, acetone and IPA for 15 minutes, respectively. Before use, the substrates were cleaned with ultraviolet ozone for 20 minutes to remove the organic residues. Then a thin layer of $\mathrm{SnO}_{2}$ was prepared by spin-coating a $\mathrm{SnO}_{2}$ dispersion (1:8.5/v:v in deionized water) at 3000 r.p.m for 30 seconds, followed by annealing in the ambient air at $150^{\circ} \mathrm{C}$ for 30 minutes. After the 20 -minute treatment by ultraviolet ozone, the substrates were transformed to the glove box. $1.5 \mathrm{M} \mathrm{PbI}_{2}$ in DMF:DMSO (9:1/v:v) was spin-coated on $\mathrm{SnO}_{2}$ at 1500 r.p.m for 40 seconds and then a 
solution of FAI:MAI:MACl (90:9:9 mg mL $\left.{ }^{-1}\right)$ in IPA was spin-coated on $\mathrm{PbI}_{2}$ at 1500 r.p.m for 30 seconds, followed by thermal annealing at $150^{\circ} \mathrm{C}$ for 15 minutes in the ambient air (ca. $30 \%$ humidity). The substrates were then transferred to the nitrogen glove box and a layer of spiro-OMeTAD or PTAA was spin-coated on perovskite film at 3000 r.p.m for 30 seconds. The spiro-OMeTAD was dissolved in chlorobenzene $\left(72.3 \mathrm{mg} \mathrm{mL}^{-1}\right)$ with additives of $17.5 \mu \mathrm{L} \mathrm{Li-TFSI/acetonitrile}\left(520 \mathrm{mg} \mathrm{mL}^{-1}\right)$ and $28.8 \mu \mathrm{L}$ tBP. The PTAA was dissolved in toluene $\left(10 \mathrm{mg} \mathrm{mL}^{-1}\right)$ with additives of $7.5 \mu \mathrm{L} \mathrm{Li-TFSI} /$ acetonitrile $(170 \mathrm{mg}$ $\mathrm{mL}^{-1}$ ) and $4 \mu \mathrm{L}$ tBP. For PSCs with CNG electrodes, the EVA or EVA-GN adhesives was spin-coated on one side of CNG at 5000, 5500 or 6000 r.p.m for 30 seconds, followed with thermal treatment at $70^{\circ} \mathrm{C}$ for 30 minutes to remove the solvent and form a thin and uniform bonding layer. The CNG electrodes were hot-pressed with semi-device (Glass/FTO/SnO $2 /$ perovskite/HTM) at $130^{\circ} \mathrm{C}$ under a pressure of $0-0.5 \mathrm{MPa}$ for $0-100$ seconds (TH-XC601-H, Shenzhen XOTECH Co., LTD.). For PSCs with control electrodes, $80 \mathrm{~nm}$ thick of Ag or Au was thermally evaporated using a black metal shading mask. The 0.09 and $1.02 \mathrm{~cm}^{2}$ masks were used to define the aperture areas during measurement.

Damp heat and operational stability tests of the control and CNG devices. For the stability tests of Fig. 4, A and B, Au electrode is used for the control devices to increase the comparability. In addition, to rule out the thermal degradation from the HTM layer, thermally stable $\mathrm{Cl}-\mathrm{GO} / \mathrm{PTAA}$ is used for control and CNG devices ${ }^{11}$.

Characterization. The Raman mapping spectroscopy was performed on an inVia spectroscope (Renishaw, UK) to assess the morphology and quality of the graphene with 
an excitation source of $532 \mathrm{~nm}$ Ar ion laser. Field emission SEM (JEOL JSM-7800F Prime) equipped with EDS was employed to observe the morphology and element distribution of the samples. An atomic force microscopy (AFM, TT2-AFM, USA) was employed to measure the roughness of $\mathrm{Cu}-\mathrm{Ni}$ substrates. The electrochemical impedance spectroscopy (EIS) and $C-V$ measurements were characterized by a multifunctional electrochemical analysis instrument (Zahner, Germany) under dark or white light $\left(60 \mathrm{~mW} \mathrm{~cm} \mathrm{~cm}^{-2}\right)$, respectively. The TPV measurements were carried out by the TranPVC instrument with a $640 \mathrm{~nm}$ laser under light-emitting diode (LED) white light bias. The $J-V$ curves of PSCs were measured under simulated solar illumination at $100 \mathrm{~mW} \mathrm{~cm}{ }^{-2}$, AM 1.5G (WXS-155S10, Wacom Denso, recorded by a digital source meter Keithley 2400). The solar simulator was calibrated by standard silicon reference cell, which was certified by the Calibration, Standards and Measurement Team at the Research Center for Photovoltaics in AIST, Japan. The spectral mismatch is $<3 \%$. The $J-V$ measurements were measured under forward scan $(-0.2$ to $1.2 \mathrm{~V})$ or reverse scan $(1.2$ to $-0.2 \mathrm{~V})$. The IPCE spectrum was characterized by a monochromatic incident light of $1 \times 10^{16}$ photon $\mathrm{cm}^{-2} 37$. The ToF-SIMS were based on ION ToF SIMS 5-100 (Germany). A stable $\mathrm{Cs}^{+}$ion beam was utilized as the ion beam to peel off the PSCs with an analysis area of $100 \times 100 \mu \mathrm{m}^{2}$. The XPS and UPS were measured with a Kratos AXIS UltraDLD by Al Ka X-ray source. The static contact angle tests were characterized by water droplet with a DSA100 instrument (Germany). The volume resistivity of bonding layer (EVA or EVA-GN) on glass was measured on a high resistance meter (Agilent 4339B, USA) to identify the percolation threshold of graphene in EVA 
polymer. The permeation rates of water vapor and oxygen for $\mathrm{Cu}-\mathrm{Ni}$ alloy and $\mathrm{CNG}$ electrodes were measured by a gas transmission rate tester followed by ISO 2556. Tafel polarization curves were obtained by an electrochemical workstation (CHI660D) with a three-electrode system. The GC-MS data was recorded by headspace GC-MS analytical methods based on a previous work ${ }^{34}$. Rt-QPLOT column $(30 \mathrm{~m} \times 0.32 \mathrm{~mm})$ or RtxVolatileAmine column $(30 \mathrm{~m} \times 0.32 \mathrm{~mm})$ was connected to the PTV inlet. The helium carrier gas was set to a constant flow, and oven equilibration time to 10 minutes.

\section{Data availability}

The data that support the findings of this study are available from the corresponding authors upon reasonable request.

\section{Code availability}

The codes used in this work are available from the corresponding authors upon reasonable request.

36 Zhang, C. Y. et al. Efficient stable graphene-based perovskite solar cells with high flexibility in device assembling via modular architecture design. Energy Environ. Sci. 12, 3585-3594, doi:10.1039/c9ee02391g (2019).

37 Wang, Y. et al. Reliable Measurement of perovskite solar cells. Adv. Mater. 31, 1803231, doi:10.1002/adma.201803231 (2019).

38 Naito, M. \& Takanashi, Y. Back surface protection sheet used for manufacturing solar cell module, comprises base material sheet, sealing material containing ethylene-vinyl acetate copolymer and fluororesin layer comprising compound 
comprising acryloyl groups. JP2015185802-A.

39 Tanabe, J., Tanaka, A. \& Kawasaki, M. Sealing film for forming solar cell module, is obtained by carrying out thermal reaction of ethylene-vinyl acetate copolymer, organic peroxide, crosslinking adjuvant as crosslinking agent and additive with self-polymerization property. JP2016092353-A. 


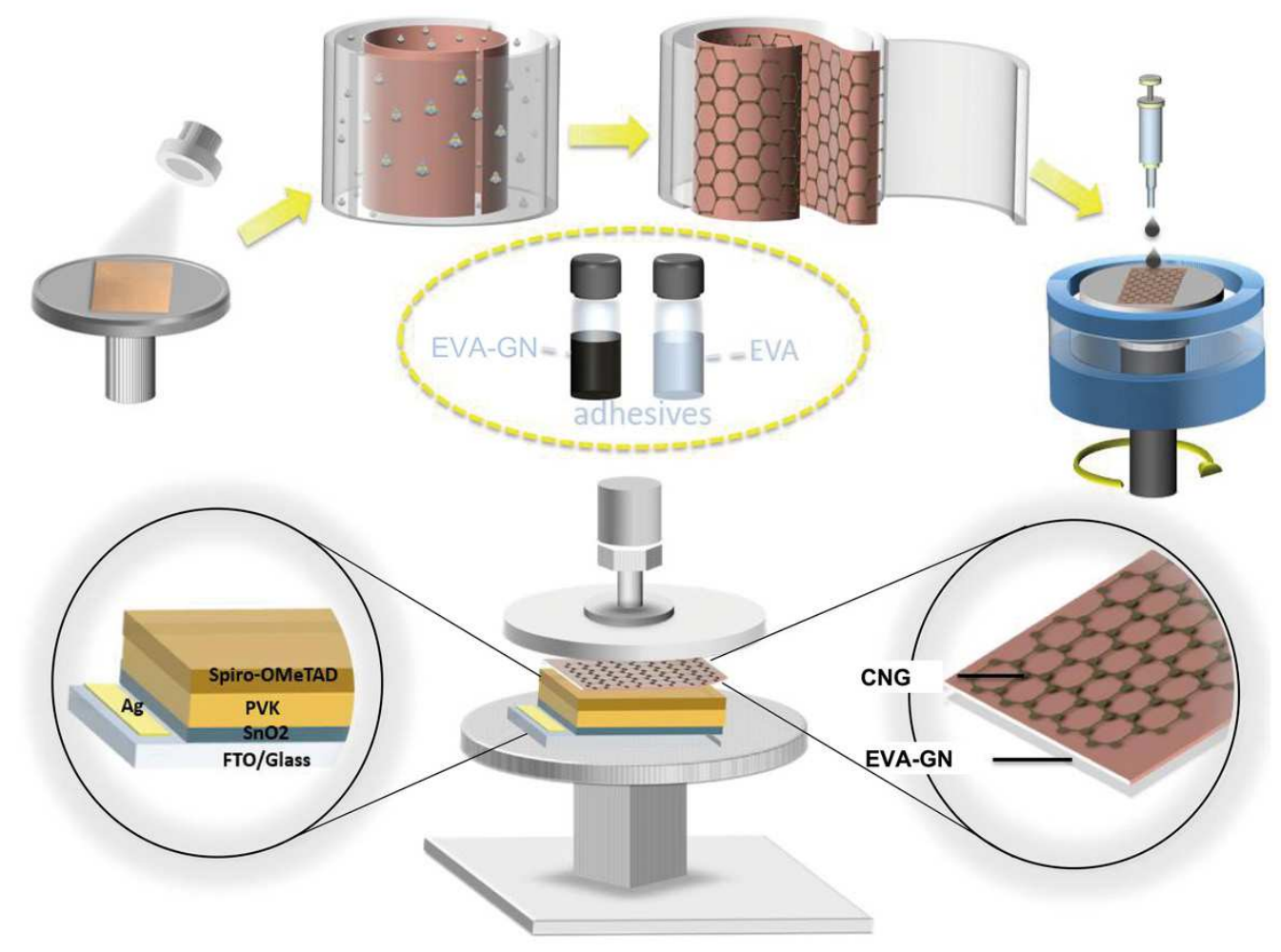

Extended Data Fig. 1. Schematic of the fabrication process of CNG electrodes and the assembly of the integral device. 

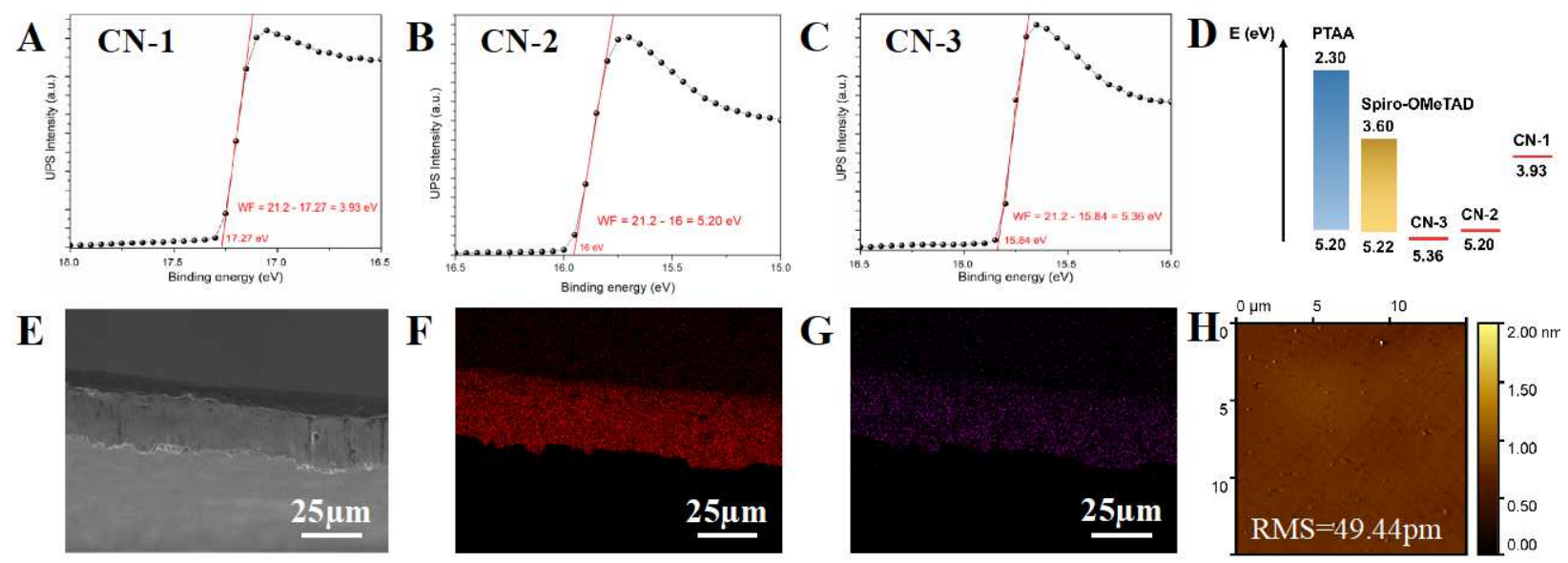

Extended Data Fig. 2. The formation and characterization of $\mathrm{Cu}-\mathrm{Ni}$ alloy. The WFs of the $\mathrm{Cu}-$ $\mathrm{Ni}$ alloys fabricated by sputtering (A) 100, (B) 200 and (C) $300 \mathrm{~nm}$ thickness of $\mathrm{Ni}$ on $\mathrm{Cu}$ foil, denoted as $\mathrm{CN}-1, \mathrm{CN}-2$ and $\mathrm{CN}-3$. (D) The relative energy level alignment of $\mathrm{CN}-1, \mathrm{CN}-2, \mathrm{CN}-3$ and the commonly used HTMs in regular PSCs. The energy band structures of HTMs are based on the previous work ${ }^{19}$. (E) Cross-sectional SEM images of CNG electrodes with EDS mapping of (F) Ni and (G) Cu elements. (H) AFM xy-plane film morphology of Cu-Ni substrate. The roughness in $(\mathrm{E})$ is caused by the preparation process of samples, which requires cutting to expose the cross section. 

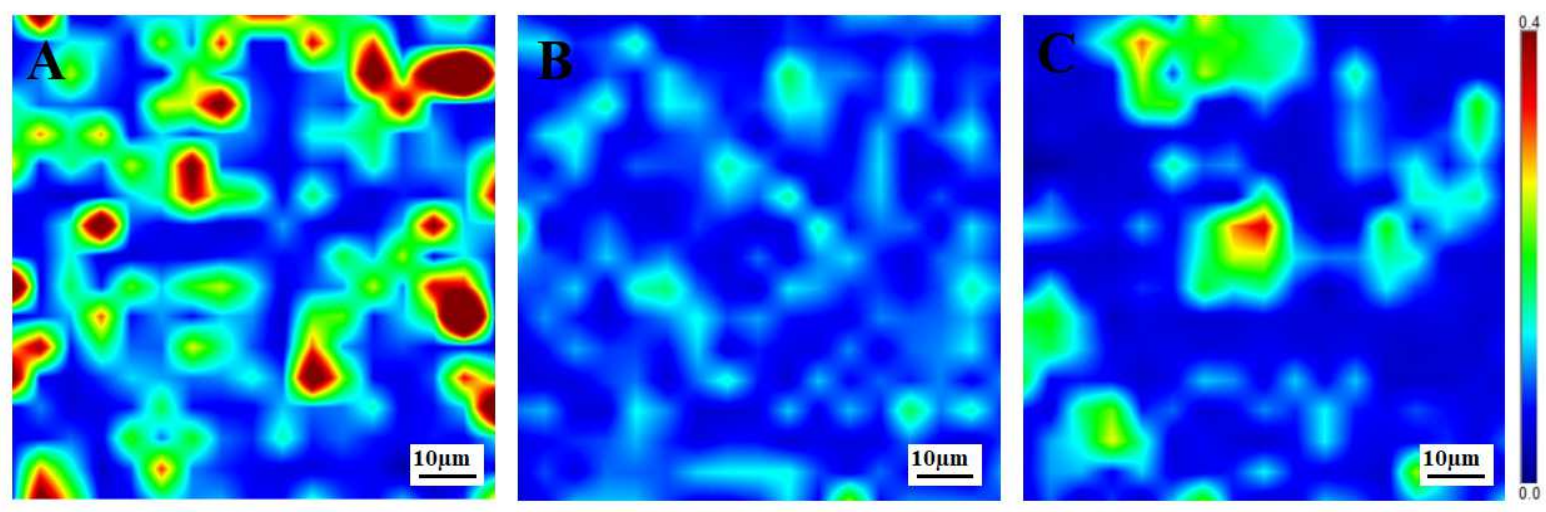

Extended Data Fig. 3. The defect density of graphene on (A) CNG-5, (B) CNG-10 and (C) CNG-15, reflected by ID/IG. 

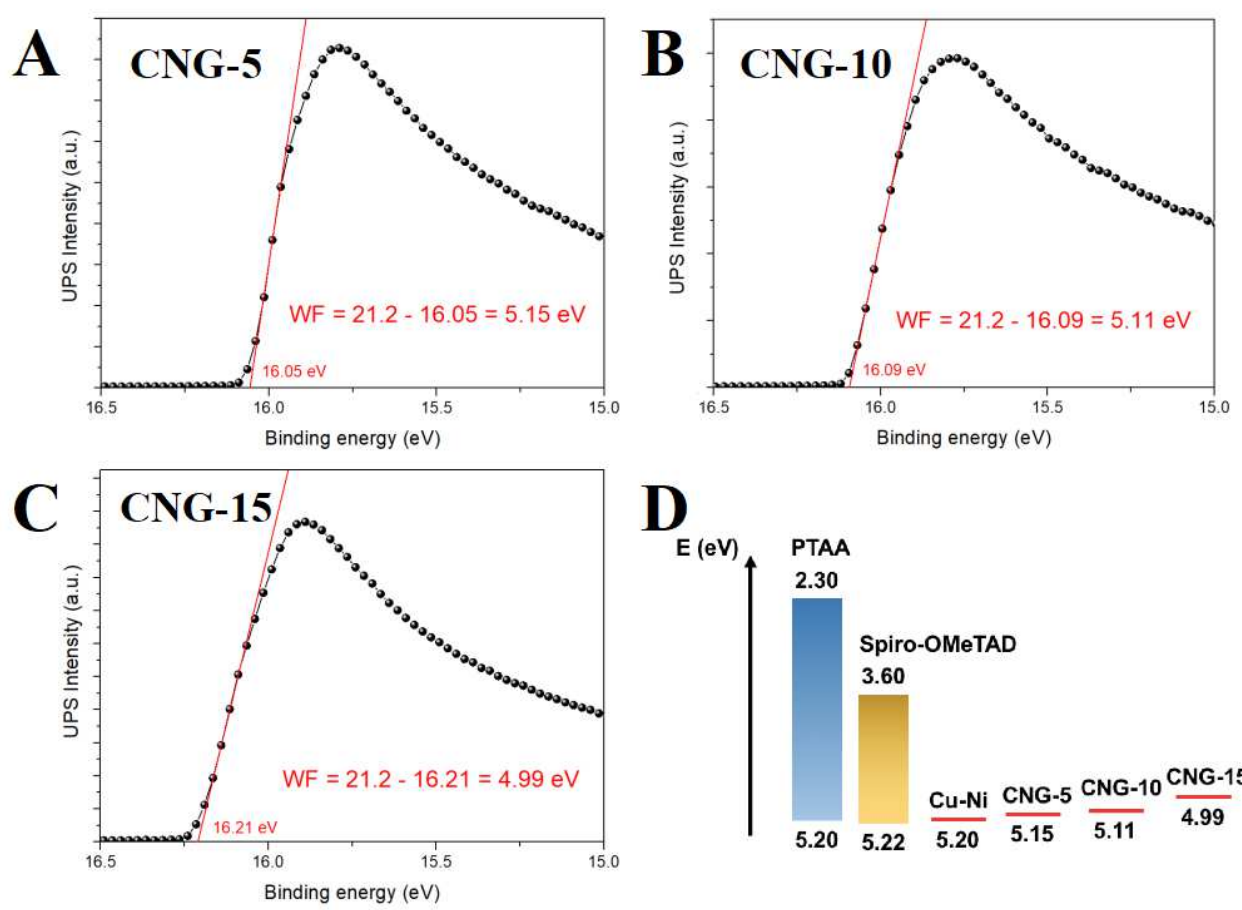

D
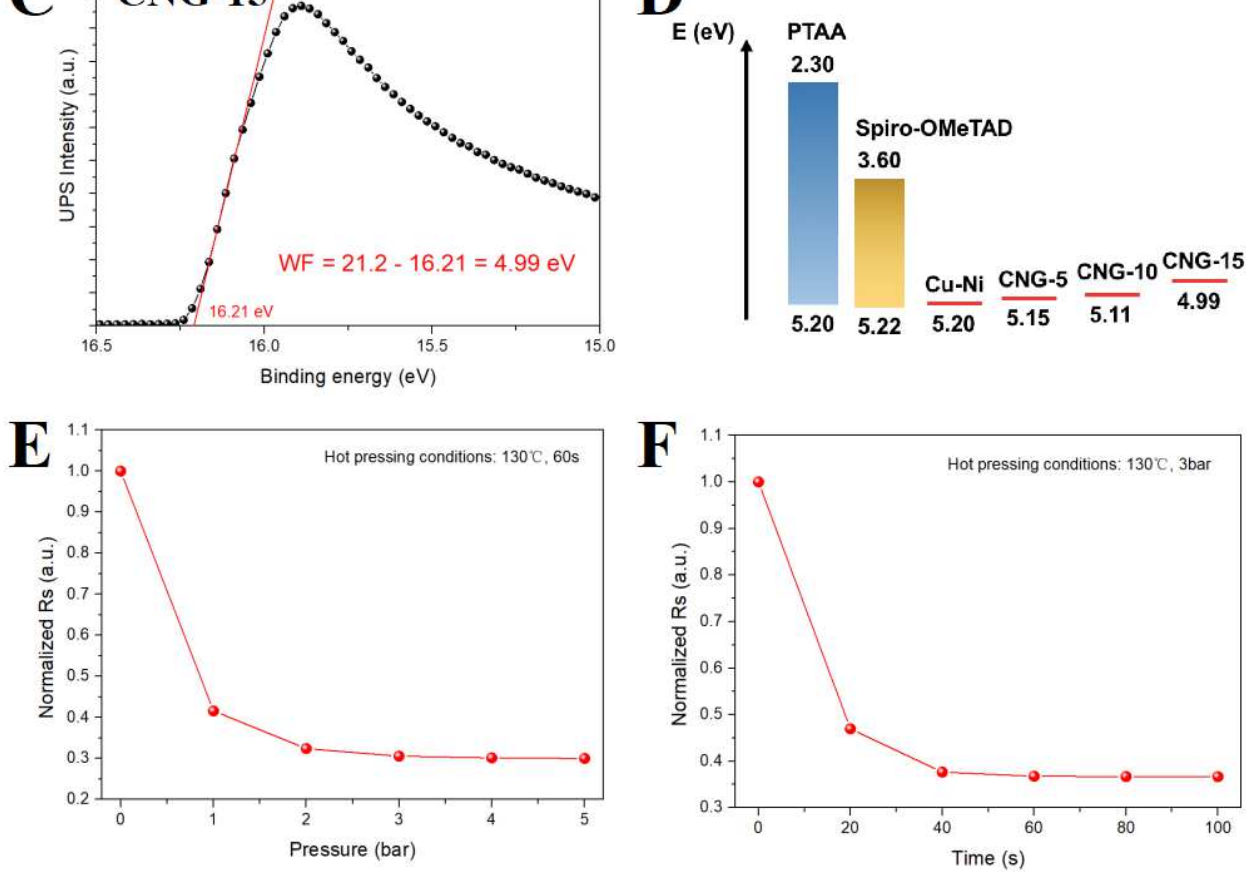

Extended Data Fig. 4. The assembly of integral CNG devices. The WFs of (A) CNG-5, (B) CNG-10 and (C) CNG-15 electrodes measured by UPS. (D) The energy level alignment for CNG electrodes and the commonly used HTMs in regular PSCs. The WF of Cu-Ni alloy in (D) is extracted from the result in Extended Data Fig. 2. The relationship between the resistance of CNG electrodes/EVA/spiro-OMeTAD/FTO and the (E) pressure and (F) time for hot pressing. The temperature is set to $130^{\circ} \mathrm{C}$ according to previous reports ${ }^{38,39}$. 

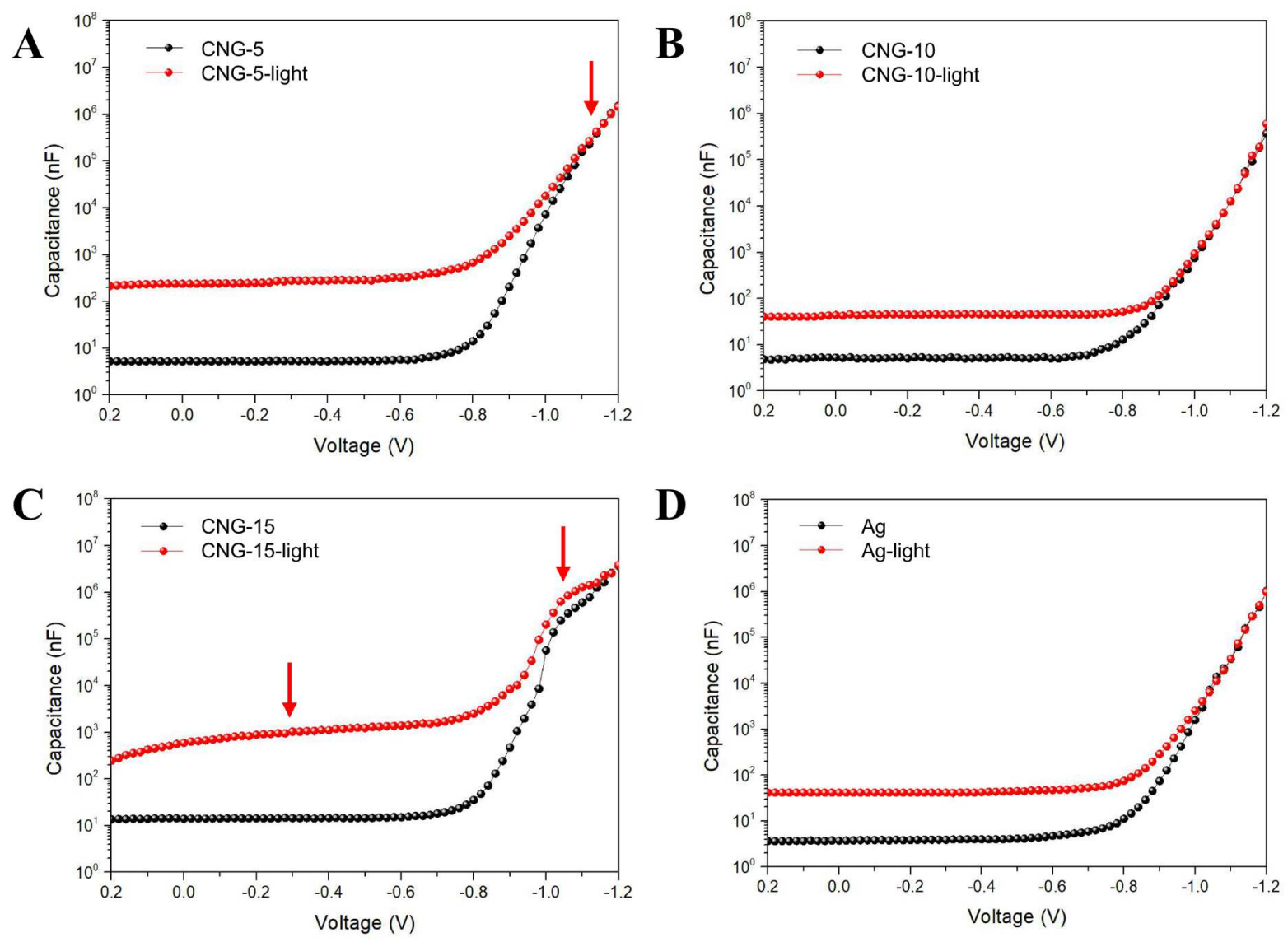

Extended Data Fig. 5. The charge carrier accumulation in CNG and Ag devices. $C-V$ characteristics of (A) CNG-5, (B) CNG-10, (C) CNG-15 and (D) Ag devices under dark or illumination (LED, white light, $60 \mathrm{~mW} \mathrm{~cm}{ }^{-2}$ ) with the frequency of $1 \mathrm{kHz}$. 


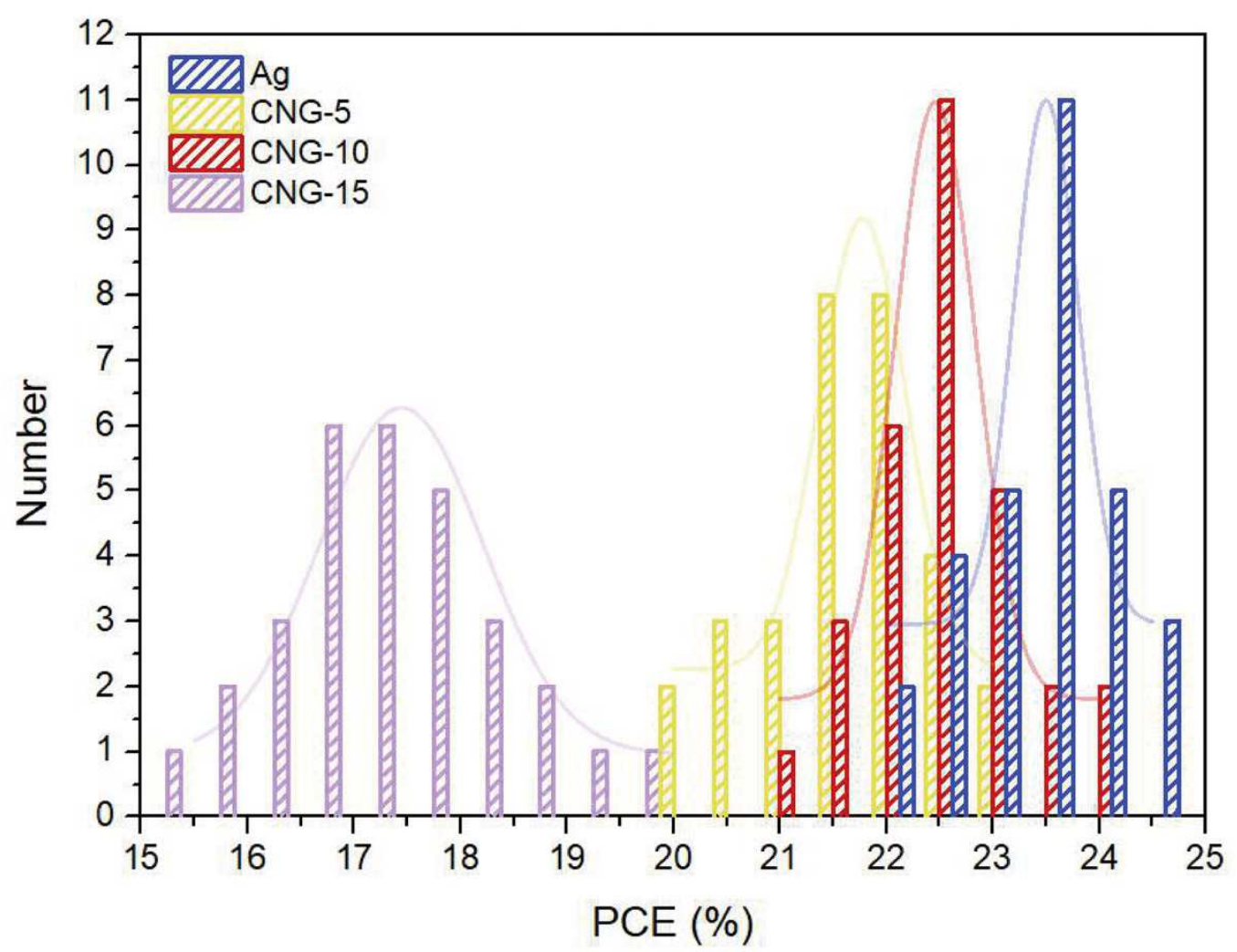

Extended Data Fig. 6. Histogram of average PCEs of PSCs using different electrodes. 

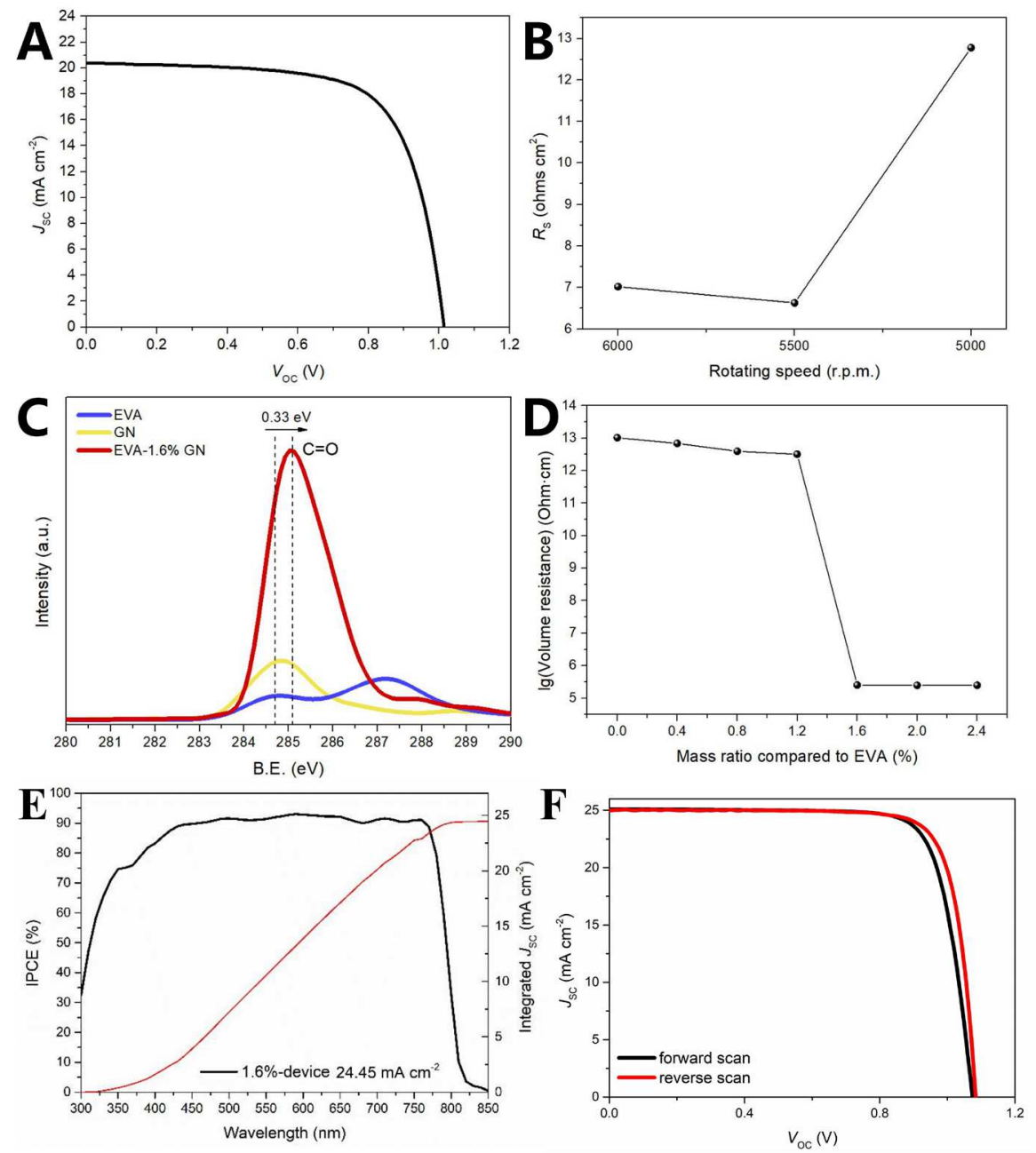

Extended Data Fig. 7. The fabrication of CNG device with an aperture area of $1.02 \mathrm{~cm}^{2}$ and the modification of the adhesive layer. (A) The $J-V$ curve of CNG-10 device under forward scan with EVA as the adhesive layer. (B) The $R_{\mathrm{S}}$ of CNG-10 device using EVA as the adhesive layer with different rotation speeds. (C) The interaction between EVA and GN. $\mathrm{C}=\mathrm{O}$ peak in EVA, GN and EVA-1.6 wt\% GN composite, measured by XPS. (D) The percolation threshold of GN in EVA adhesive. (E) The IPCE spectrum and (F) the $J-V$ curves under forward and reverse scan for 1.6\%device. 


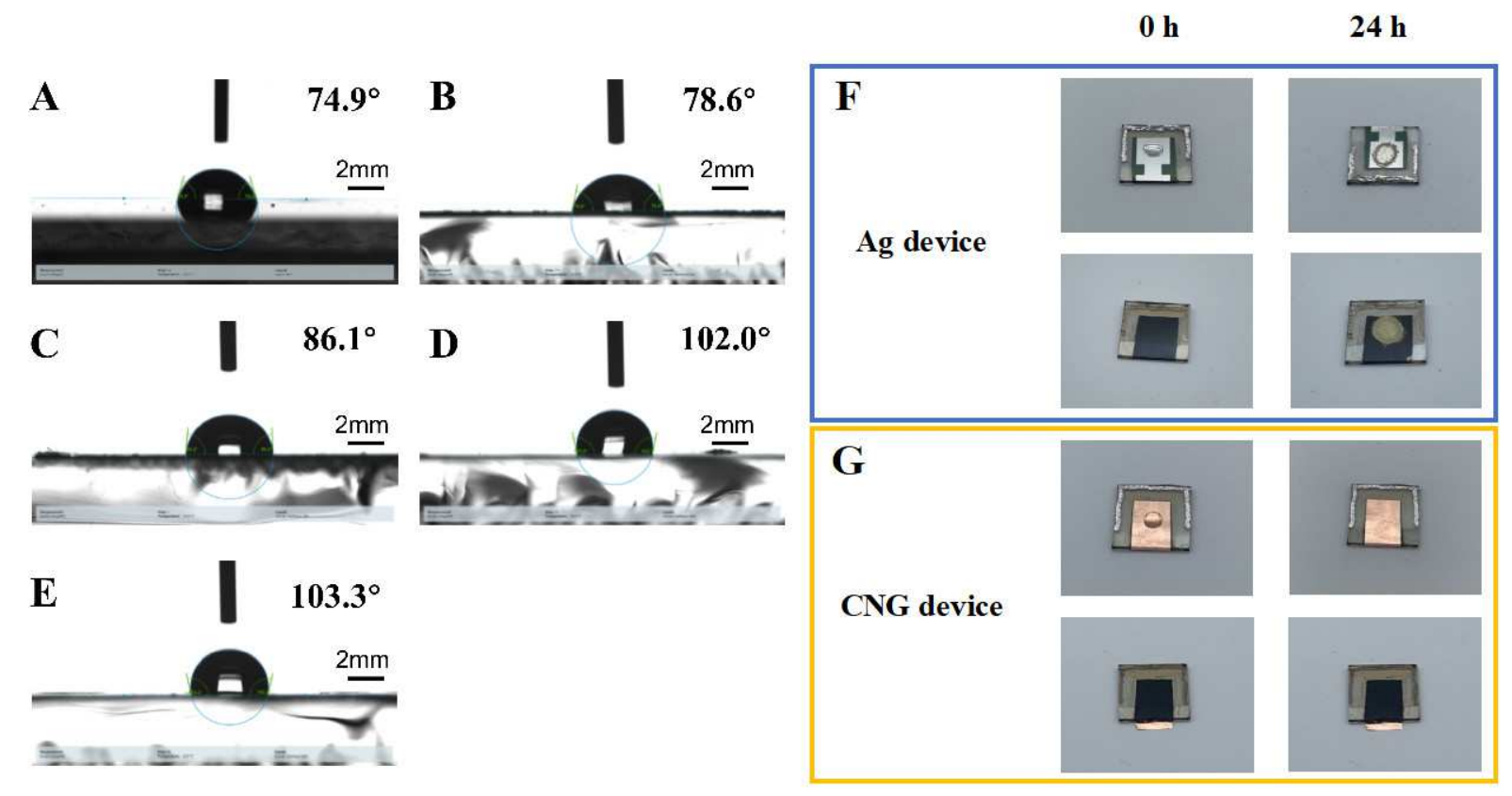

Extended Data Fig. 8. The hydrophobic property of CNG electrodes. The static contact angle with water in air for (A) Ag, (B) Cu-Ni alloy, (C) CNG-5, (D) CNG-10 and (E) CNG-15, respectively. The top and bottom photographs of PSCs with (F) Ag and (G) CNG-10 electrodes before (left) and after (right) being exposed to water droplet for 24 hours. 

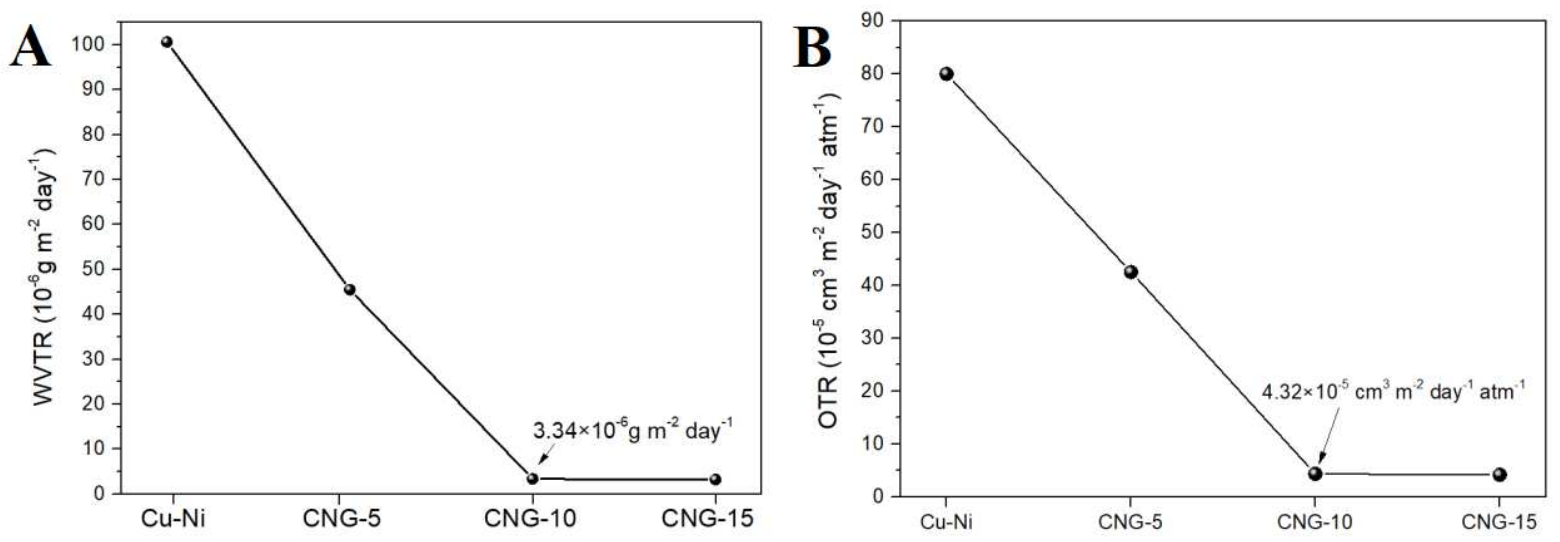

Extended Data Fig. 9. The effect of graphene on the resistance of CNG electrodes to water vapor and oxygen. The permeation rates of (A) water vapor and (B) oxygen for $\mathrm{Cu}-\mathrm{Ni}$ alloy and CNG electrodes. 

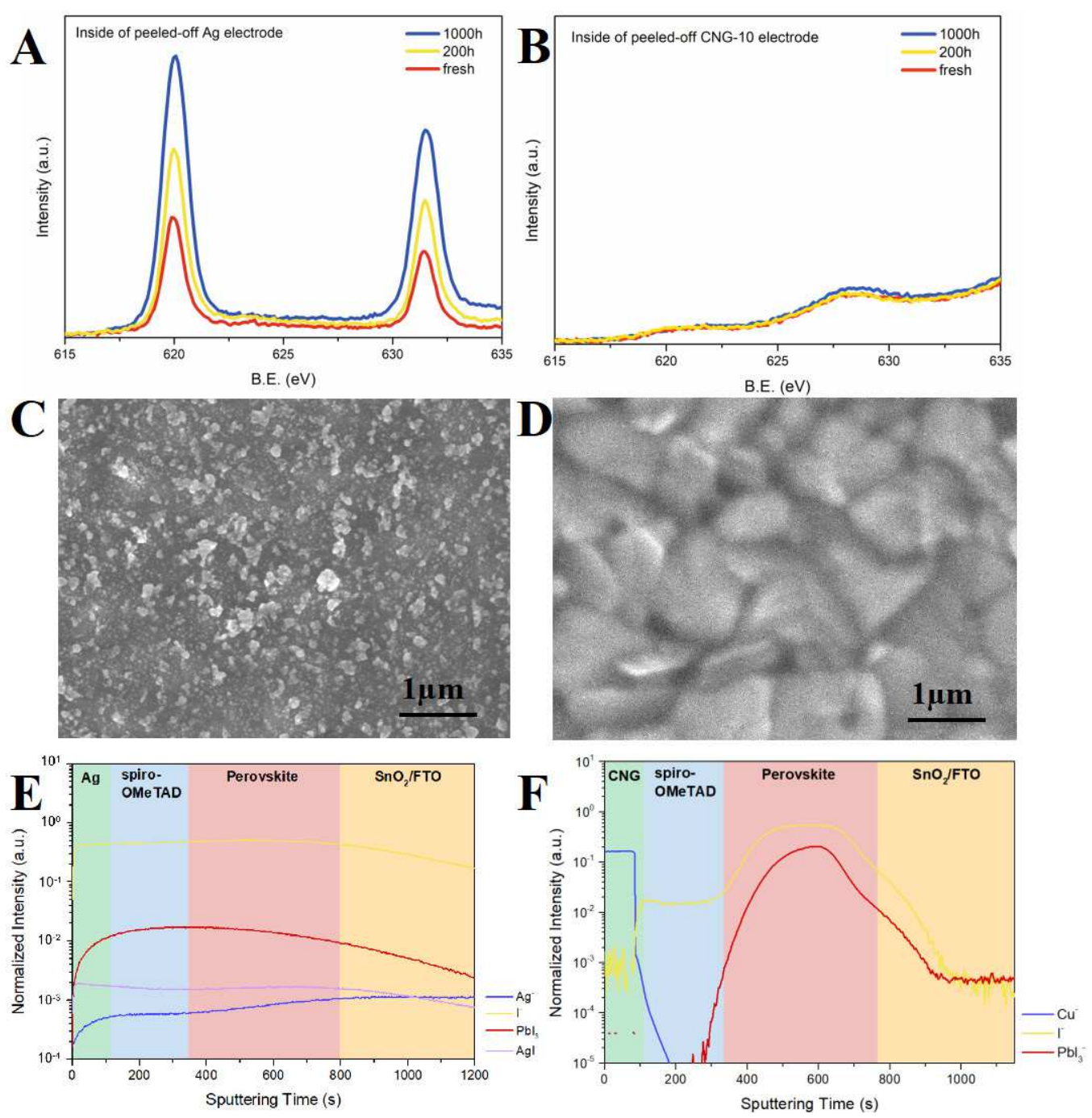

Extended Data Fig. 10. The suppression of halide ions and metal atoms diffusion by

CNG-10 electrode. The XPS spectra of I 3d core levels of the inside of (A) Ag and (B) CNG-10 electrodes of PSCs with different aging time. The top-view SEM images of spiro$\mathrm{OMeTAD} /$ perovskite/ $\mathrm{SnO}_{2} / \mathrm{FTO} /$ glass after peeling off the electrodes of aged (C) Ag and (D) CNG-10 devices. The depth profiles of ToF-SIMS for aged (E) Ag and (F) CNG-10 devices. 
Extended Data Table 1. The champion performance of Ag and CNG devices with an aperture area of $0.09 \mathrm{~cm}^{2}$.

\begin{tabular}{lllllll}
\hline Rear electrode & $\begin{array}{l}V_{\mathrm{OC}} \\
(\mathrm{V})\end{array}$ & $\begin{array}{l}J_{\mathrm{SC}} \\
\left.(\mathrm{mA} \mathrm{cm})^{-2}\right)\end{array}$ & $\begin{array}{l}\mathrm{FF} \\
(\%)\end{array}$ & $\begin{array}{l}\mathrm{PCE} \\
(\%)\end{array}$ & $\begin{array}{l}R_{\mathrm{S}} \\
\left(\mathrm{Ohm} \mathrm{cm}^{2}\right)\end{array}$ & $\begin{array}{l}R_{\mathrm{sh}} \\
\left(\mathrm{Ohm} \mathrm{cm}^{2}\right)\end{array}$ \\
\hline $\mathrm{Ag}$ & 1.162 & 26.23 & 80.91 & 24.65 & 2.61 & 16198.52 \\
$\mathrm{CNG}-5$ & 1.136 & 25.75 & 79.53 & 23.27 & 3.46 & 10067.85 \\
$\mathrm{CNG}-10$ & 1.154 & 26.16 & 80.66 & 24.34 & 2.88 & 13503.61 \\
$\mathrm{CNG}-15$ & 1.081 & 24.60 & 75.30 & 20.03 & 4.16 & 9489.08 \\
\hline
\end{tabular}

